\title{
VII. NATION UND KULTUR
}

1. Paris: Zwischen universaler Inklusion und politischem Bekenntnis

Seit den frühen 1880er Jahren entstanden in Paris öffentliche Denkmäler für Literaten und Künstler. Meist in bescheidenem Festrahmen, feierte man hier das kulturelle Erbe der Nation mit inklusiven Visionen, zu denen soziale Diversifikation nach innen und nationalstaatliche Grenzen nach außen gehörten, während militärische Assoziationen nicht vorkamen.

Etwa die Stifter eines Denkmals für den Romancier Alexandre Dumas auf der Place Malesherbes im November 1883 hoben vor einer kleinen, vor allem aus Künstlern bestehenden Festgemeinde ${ }^{1}$ darauf $a b$, daß Dumas' Name nicht nur in Frankreich Klang hatte ${ }^{2}$. Der nationale Verdienst des Literaten bestand gerade darin, als ein über die nationalen Grenzen hinauswirkendes, werbendes Prinzip eine universale literarische Kunst zu vertreten, die im internationalen Urteil auf den "génie« Frankreichs zurückstrahlte. Schichtenübergreifende Rezeption innerhalb Frankreichs und transnationale Attraktivität seiner Literatur im Ausland motivierten die Denkmalsetzung für den literarischen Patrioten. Akzentuiert wurde darüber hinaus die innerfranzösische Wirkung des Romanciers als Konsensfigur jenseits innenpolitischer Fraktionierungen, deren Frankreich bedurfte und in denen es sich geeint wiederfand ${ }^{3}$.

Das universalistisch-inklusive Deutungskonzept stand selbst nicht-französischem Personal offen. Es bestimmte etwa die Errichtung einer ShakespeareStatue Mitte Oktober 1888 an der Avenue Messine im 8. Arrondissement ${ }^{4}$. Die Shakespeare-Figur, die dem Conseil Municipal geschenkt worden war, verwies der Inszenierung zufolge völkerverbindend auf den wrespect pour le génie humain " ". Universale Werte der Humanität und Kunst schufen dieser Diktion zufolge Loyalitäten jenseits nationaler Zugehörigkeit und zugleich erwies sich diejenige Nation als universalistisch und freiheitlich, die selbst das andersnationale Genie in ihre Kultur zu inkorporieren wußte.

Die drastische Häufung monumentaler Künstler-Ehrungen verwässerte die Programmatik der Projekte mitunter erheblich. Etwa 1902 kamen drei Künst-

Vgl. Le Temps, 6. November 1883, S. 2.

Vgl. [An.,] Le monument d'Alexandre Dumas, S. 3.

Vgl. ibid. S. 25.

Acceptation d'une statue (...), séance du 22 juin 1888, in: CMPV, Année 1888, $1^{\text {er }}$ sem., S. $969 f$.

5 Rapport de M. Emile Richard sur l'offre d'une statue de William Shakespeare, faite par M. Knighton à la ville de Paris, in: CMRD, Année 1888, Imp. $\mathrm{N}^{\circ} 68, \mathrm{~S}$. 1-2. 
lerdenkmäler ${ }^{6}, 1906$ sogar vier ${ }^{7}$ zustande. Überlastungserscheinungen vor allem in Parks und Grünflächen bewogen den Conseil Municipal im Zusammenhang mit der Errichtung des Denkmals für den Komponisten Benjamin Godard im Sommer $1906^{8}$, den Parc Monceau und die Champs Elysées für weitere öffentliche Denkmäler zu sperren, da sie sich andernfalls in "véritables nécropoles « zu verwandeln drohten".

Mit der wachsenden Zahl der Künstlerehrungen dominierten weitgehend entpolitisierte Zeremonien. Die Konnotierung mit der republikanischen Nation blieb zweitrangig, ohne jedoch aus dem Blickfeld zu verschwinden. So erachteten die Stifter einer Büste für den Literaten Ferdinand Fabre den Jardin du Luxembourg als "Westminster en plein air ${ }^{10}$, oder die Initiatoren eines Honoré de Balzac-Denkmals dessen Standort auf der Place du Palais Royal als "Panthéon à ciel ouvert « ${ }^{11}$, als quasi-sakralen Hort der Kulturheroen, die Frankreich in Konkurrenz zu England ebenfalls für sich reklamieren wollte ${ }^{12}$.

Prominent blieb bei den Literatenehrungen der Rekurs auf die französische Sprache als dem konstitutiven Medium der Nation. So stand etwa Gabriel Vicaire seinen Stiftern zufolge für die

6 Im Mai 1902 erhielt Alphonse Daudet eine Statue im Jardin des Champs Elysées. Vgl. Brief vom Präsidenten der Société des gens de lettres an den Innenminister, 19. Mai 1902, $A N F^{\text {lc }}$ I 170 Dossier: 16 janvier 1902-17 mai 1902. Érection d'un monument à Alphonse Daudet. Im Oktober des Jahres ehrte man Gabriel Vicaire mit einer Büste im Jardin du Luxembourg. Vgl. Inauguration du buste de Gabriel Vicaire dans le Jardin du Luxembourg à Paris, le 23 octobre 1902. Discours et vers, Bourg-en-Bresse 1902. Am 22. November bekam Honoré de Balzac eine Statue an der Avenue de Friedland im westlichen 8. Arrondissement. Vgl. L'Événement, 19. Juni 1891, Le Figaro, 19. Juni 1891, AN F ${ }^{21} 4855$ Dossier: Monument Balzac, place du Palais Royal, 6 aout 1888-7 mars 1904; 14-21 avril 1936 [up]. Vgl. dazu Jacques DE CASO, Rodin and the cult of Balzac, in: Sculpture Review 47 (1998) S. 279-284.

7 Am 23. Februar 1906 wurde eine Statue für Alfred de Musset im Parc Monceau eingeweiht. Vgl. u.a. Érection sur la place du Théâtre Français (...), séance du 11 juillet 1904, in: CMPV, Année 1904, $2^{\mathrm{e}}$ sem., S. 260. Dazu kam am 27. Mai 1906 ein Standbild für Corneille auf der Place du Panthéon. Vgl. [An.,] Inauguration du monument élevé à Pierre Corneille, à Paris, le dimanche 27 mai 1906, Paris 1906. Ein weiteres Dumas-Denkmal folgte am 12. Juni 1906 auf der Place Malesherbes. Vgl. Le Temps, 18. Juni 1906, supplément, S. 1-2 und [An.,] Inauguration de la statue d'Alexandre Dumas à Paris, le mardi 12 juin 1906, Paris 1906. Dazu kam schließlich am 22. Juli 1906 ein Denkmal für Armand Silvestre im Jardin Cours-la-Reine.

8 Vgl. Memorandum vom 3. Mai 1906, AN F $^{21} 4865$ Dossier: Monument Benjamin Godard [up].

9 Vgl. Rejet (...), séance du 19 avril 1905, in: CMPV, Année 1905, $1^{\text {er }}$ sem., S. 597-598.

10 Le Temps, 15. Juni 1903, S. 3.

"Érection, place du Palais Royal, de la statue de Balzac, séance du 17 juin 1891, in: CMPV, Année 1891, $1^{\text {er }}$ sem., S. 890-893, hier S. 892.

12 Vgl. Le Temps, 15. Juni 1903, S. 3 und [An.,] Le Monument de Ferdinand Fabre, 14 juin 1903, Paris 1903, S. 12, 15. 
Langue de notre patrie! (...) Elle reflète l'histoire humaine d'un pays (...). Elle est fait de la vie profonde et lointaine d'une collectivité d'êtres et de la vie courante. (...) Elle est l'expression enthousiaste, passionnée des souvenirs, des douleurs, des joies et des espérances ${ }^{13}$ !

Die französische Sprache erschien damit als ebenso rationales wie affektives Medium nationaler Verständigung und Kontinuitätsstiftung über die Generationen hinweg; sie ermöglichte, konstituierte die Nation als kommunikative und Erinnerungs-Gemeinschaft. Für die Stiftung zahlreicher Literatendenkmäler erwies sich dieses Deutungsmuster als repräsentativ.

Jenseits der inflationären Denkmalschwemme entstanden mit distinkten Deutungsmustern Monumente für die großen politischen Geister der Epoche, die gleichermaßen als Intellektuelle wie als kritische Republikaner öffentliches Profil gewonnen hatten. So konnte Ende Februar 1902 ein Denkmal für den renommierten Schriftsteller und engagierten Republikaner Victor Hugo auf dem gleichnamigen Platz im 16. Arrondissement eingeweiht werden. Die Stilisierung Hugos zur Kultfigur der republikanischen Nation war zu diesem Zeitpunkt freilich bereits seit dem dramatisch inszenierten Staatsbegräbnis vom Juni 1885 präfiguriert ${ }^{14}$. Die Denkmaleinweihung vom Frühjahr 1902 war nun ihrerseits rituell in die landesweit durchgeführte Hundertjahrfeier zu Ehren Hugos eingebunden.

Zunächst war eine Hugo-Büste im Pantheon als neuerliches Kultobjekt im Beisein der politischen und militärischen Elite der Republik einschließlich des Staatspräsidenten Loubet gefeiert worden ${ }^{15}$. Später enthüllte man ein Denkmal auf der Place Victor Hugo in Anwesenheit des Ministerpräsidenten WaldeckRousseau und des Staatspräsidenten sowie weiterer Minister, Parlaments- und Conseil-Mitglieder ${ }^{16}$. Sie brach die Exklusivität des offiziellen Staatsaktes im Pantheon wieder zugunsten der Feier im öffentlichen Raum auf. Erinnert wurde an Hugos Rückkehr aus dem Exil 1871 und sein Engagement für die »France républicaine (...) réuni[e] et uni[e]« als Abgeordneter und später Senator. Darüber hinaus stand er inzwischen den Rednern zufolge als »apôtre social« längst für eine auf »égalité« und »fraternité« verpflichtete Nation ${ }^{17}$.

Die Konsensrhetorik ermutigte bisweilen sogar dazu, nun auch Hugos Rolle während der Julimonarchie und der Revolution von 1848 durchaus kritisch zu

$13 \mathrm{Vgl}$. [An.,] Inauguration du buste de Gabriel Vicaire, S. 9.

14 Vgl. BEN-AMOS, Les funérailles de Victor Hugo, passim.

15 Vgl. Le Siècle, 27. Februar 1902, S. 1-2.

16 Vgl. ibid. S. 2; Le Temps, 27. Februar 1902, S. 2. Vgl. auch Monument de Victor Hugo. Médaillons de Charles Hugo, François-Victor Hugo, Paul Meurice, Auguste Vacquerie. Cérémonie d'inauguration 20 juin 1910, Paris 1910. Das am 28. September 1909 im Garten des Palais Royal eingeweihte Hugo-Denkmal von Rodin war eine staatliche Auftragsarbeit; vgl. Le Gaulois, 25. September 1909, S. 1 [G. DROULLY]. Vgl. aus kunsthistorischer Perspektive Ruth BUTLER, The politics of public monuments. Rodin's Victor Hugo and Balzac, in: Sculpture Review 47 (1998) S. 8-15.

17 Vgl. Le Temps, 27. Februar 1902, S. 2. 
kommentieren. So wurde nun daran erinnert, daß Hugo durchaus zu den groBen Schöpfern der »épopée impériale« gezählt hatte, zu den Legendenschmieden der "gloires napoléoniennes« während der 1830er Jahre, die dem Revolutionsvollender und Reformer Napoleon I. galten ${ }^{18}$. Als politische Fehleinschätzung wurde ebenso offen Hugos Votum zugunsten der Präsidentschaftskandidatur des Prinzen Louis-Bonaparte in der Zweiten Republik qualifiziert. Dergleichen Vorwürfe trafen indessen die historische Figur, die sich von dieser politischen Vorgeschichte gleichsam in einem Akt der Sühne im Exil abwandte, um als Apologet der republikanisch verfaßten Nation wiederzukehren. Gerade deshalb verkörperte Hugo die Nation am Ende umso authentischer und versöhnlicher, weil seine eigene Vita die Regimebrüche und Diskontinuitäten und die widerstreitenden »émotions de trois générations d'hommes« nicht nur widerspiegelte, sondern durch ein biographisches Kontinuum und die dabei durchlebte "transformation « politischer Überzeugungen verband ${ }^{19}$.

Erst lange nach dem Ersten Weltkrieg sollte mit dem Denkmal für Émile Zola 1924 eine Figur vergleichbaren Renommees und nationaler Valenz geehrt werden. Die Initiative dazu war allerdings noch deutlich vor dem Krieg zustandegekommen, indem sich im Dezember 1902 aus den Reihen der republikanischen Ligue des droits de l'homme ein Komitee unter der Präsidentschaft des Vorsitzenden der Ligue Francis de Pressensé bildete, dem weiter Ludovic Trarieux und Oberstleutnant Picquard angehörten ${ }^{20}$.

Schon die personelle Zusammensetzung des Komitees machte den Motivationszusammenhang mit der Dreyfus-Krise als dem großen Diskurs über die ethnisch-religiös exklusive Nation deutlich. Pressensé klagte in der Tat über Schwierigkeiten bei dem Versuch, eine städtische oder staatliche Genehmigung für einen Standort zu erhalten, so daß ihm die Nation für die Ehrung des "grand serviteur du droit« politisch noch nicht reif genug schien ${ }^{21}$. Daß die organisatorischen Hemmnisse, die sich der Denkmalerrichtung in den Weg stellten, faktisch auf eine Obstruktion gegen den »auteur de ,J'accuse«" und also Zola als den Verfasser jenes aufsehenerregenden Artikels im Aurore vom Januar 1898 hinauslief, der ihn zu einem der prominentesten Dreyfus-Verteidiger und Kläger gegen das französische Justizsystem gemacht hatte, deutete Pressensé provokant an ${ }^{22}$.

Eine monumentale Reminiszenz an die Figur, die für die Klage der Nation gegen sich selbst stand, scheint nicht nur von Konservativen, sondern auch von

18 Vgl. Le Siècle, 27. Februar 1902, S. 3 [DOMBASLE]

19 Vgl. ibid.

20 Vgl. Bulletin officiel de la Ligue des Droits de l'homme 3 (1903) S. 121-122.

21 Vgl. Pressensé an den Sous-secrétaire d'État Dujardin-Beaumetz am 3. Juni 1910, AN F ${ }^{21}$ 4857 Dossier: Monument Émile Zola, par Constantin Meunier, 3 juin 1910-2 juin 1914.

22 Vgl. Question de M. Le Menuet sur l'emplacement de la statue d'Émile Zola, séance du 3 avril 1908, in: CMPV, Année 1908, S. 979-982, hier besonders S. 981. 
gemäßigten Republikanern im Conseil als unerwünschte Provokation erachtet worden $\mathrm{zu}$ sein. Ein neuerlicher Vorstoß einer Gruppe von Conseil-Mitgliedern 1913, die Statue auf dem Boulevard de Clichy zu errichten, nahm sich als vermittelnde Deutungsversion aus, denn der Antrag zielte deutlich weniger auf den politisch engagierten Literaten als auf den volksnahen, die "foule» ihrer sozialen und moralischen Befindlichkeit nach skizzierenden "Zola écrivain, littérateur, d'école illustre«, der in diesem Quartier auch gelebt und die soziale Anschauung für seine Romane gewonnen habe ${ }^{23}$. Die Einweihung des Zola-Denkmals im westlichen 15. Arrondissement, zusätzlich verschleppt in den Kriegsjahren, erwies sich über den Querelen dann erst im Juni 1924 als möglich $^{24}$. Der antisemitische Rechtsnationalismus, der Zola zum erbitterten Kritiker hatte werden lassen, wurde nun nicht mehr thematisiert. Statt dessen spiegelten die Reden ein Selbstbewußtsein wider, demzufolge nach dem gewonnenen Krieg die moralische Regeneration der Nation abgeschlossen und über alle Zweifel erhaben schien.

2. Berlin: »Dichter und Denker« zwischen Emanzipation und saturiertem Machtstaat

\subsection{Ambivalenz, Redundanz und Exklusion: Umbrucheffekte im Schiller-, Goethe- und Lessing-Kult nach 1871}

Die Rezeption der Denkmäler für Schiller (1871), Goethe (1880) und Lessing (1890) unterlag, ursprünglich auf eine Berliner Initiative aus den 1860er Jahren zurückgehend, über der Zäsur der Reichsgründung spezifischen Modifikationen. Während sich differierende Schiller-Deutungen auch nach 1871 hielten, unterlag die Goethe-Figur bis zu ihrer Inszenierung deutlichem Bedeutungsverschleiß; an die Lessing-Figur schließlich lagerten sich im voranschreitenden Jahrhundert Ausgrenzungsdiskurse an.

Ein ungleich höheres Maß an öffentlicher Aufmerksamkeit als dem Anfang Juni 1871 errichteten Hegel-Denkmal ${ }^{25}$ und eine dezidiert nationale Konnotie-

Vgl. Proposition, in: CMRD, Année 1913, N 98, S. 2; Renvoi (...), séance du 14 november 1913, in: CMPV, Année 1913, $2^{c}$ partie, S. $184 f$.

24

Vgl. Le Temps, 16. Juni 1924, S. 4.

25 Vgl. Memorandum zur Errichtung der Hegelbüste, GStA PK I. HA Rep. 93 B Nr. 2365, BI. 16. Die Denkmalerrichtung am 3. Juni 1871 ist falsch datiert bei Hans-Martin SASS, Hegel feiern!, in: GRMMM, HERMAND (Hg.), Deutsche Feiern, S. 62-78, hier S. 62. Vgl. Spenersche Zeitung, 4. Juni 1871, LAB A Rep. 000-02-01 Nr. 1632, NPKZ, 6. Juni 1871, S. 2; VZ, 4. Juni 1871, 2. B., S. 2; [An.,] Hegels Säcularfeier, in: Der Gedanke. Zeitschrift 
rung kam zunächst dem Berliner Schiller-Denkmal zu, das, als es am 10. November im gleichen Jahr und zu Schillers Geburtstagsjubiläum auf dem Gendarmenmarkt am Treppenaufgang vor dem Schauspielhaus eingeweiht wurde $^{26}$, bereits eine langwierige Projektphase hinter sich hatte. Die Initiative ging ursprünglich von einem Berliner Komitee im Kontext landesweiter Schiller-Feiern nach dessen 50. Todestag 1855 aus, die in zahlreichen deutschen Staaten zu Festumzügen und Denkmalenthüllungen geführt hatten ${ }^{27}$.

Als Ausdruck verbreiteter Schiller- und Literatenemphase hatten im Umfeld des Berliner Projekts darüberhinaus zwei Berliner Buchhändler angeregt, Unter den Linden eine ganze »Reihe von öffentlichen Denkmälern« für deutsche Dichter zu erbauen. Die Verfasser hielten die monumentale Ehrung der "grossen Männer unserer Nation, die um das Geistesleben der ganzen Menschheit so unberechenbare Verdienste sich erworben«, einmal mehr im Vergleich mit »dem Auslande « für geboten ${ }^{28}$. Von einer Folge kolossaler Büsten zunächst Schillers, Goethes, Lessings und Alexander von Humboldts, »eine[r] Art Walhalla unter freiem Himmel« und "wahrhaften Nationalgalerie sich nicht nur einen pädagogischen Effekt auf »unsere Jugend«, sondern auch die kollektive Inspirierung eines "wahrhaft tüchtigen Nationalbewußtseins, ja Nationalstolzes ${ }^{29}$. Die Idee, die staatlich-politisch nicht erreichte nationale Einung durch einen intensiven Kult der »Geistesheroen « herbeiführen zu können, war ebenso konstitutiv für diese Denkfigur wie die Überzeugung vom Identitätsstiftungseffekt, den bereits die öffentliche visuelle Exponierung des Denker- und Dichterpersonals nach sich ziehen sollte. Nicht zuletzt war die Denkmalgalerie auch als monumentale Replik auf die Münchner "Bavaria» erstrebt und sollte nun das Nations-Gefühl primär auf »Preußen« lenken ${ }^{30}$. Das Projekt sollte durch eine öffentliche Subskription finanziert und die Königliche Akademie der Wissenschaften unter dem Vorbehalt des monarchischen Plazets befugt werden, per Majoritätsbeschluß je neu darüber zu entscheiden, wer

für wissenschaftliche Forschung und Kritik. Organ der Philosophischen Gesellschaft zu Berlin 8 (1871) S. 122-165.

Vgl. zum Folgenden NPKZ, 11. November 1871, S. 1; Germania, 11. November 1871, S. 1; NAZ, 11. November 1871, S. 1, in: [An.,] Schiller-Denkmal Berlin 1871, Bd. 1, Berlin 1871 [archivalischer Sammelband], Bl. 4.

Vgl. Rainer NOLTENIUS, Schiller als Führer und Heiland. Das Schillerfest als nationaler Traum von der Geburt des zweiten deutschen Kaiserreichs, in: DUDING u.a. (Hg.), Festkultur, S. 237-257. Allerdings verbindet NOLTENIUS, S. 256, ohne Vergleichsperspektive undifferenziert den Dichterkult nach 1871 mit dem Führerkult des Nationalsozialismus. Vgl. auch DERS., Dichterfeiern in Deutschland. Rezeptionsgeschichte als Sozialgeschichte am Beispiel der Schiller- und Freiligrath-Feiern, München 1984, hier S. 144-156.

28 Vgl. Hermann KAISER, G.W.F. MÚLLER, Vorschlag zur Errichtung einer Reihe von Denkmälern berühmter deutscher Männer Unter den Linden in Berlin, Berlin 1859, S. 3-4, in: LAB A Rep. 000-02-01 Nr. 1634, Bl. 2.

${ }^{29}$ Ibid. S. 5 [H. i. O.].

${ }^{30} \mathrm{Vgl}$. ibid. S. 6 [Seitenzählung der Denkschrift]. 
Aufnahme in die Monumentalreihe finden sollte ${ }^{31}$. Eine öffentliche Diskussion des Vorschlags blieb indessen aus.

Die Kollision des Berliner Projekts für ein Schiller-Denkmal mit vergleichbaren Unternehmungen zugunsten eines Goethe- und eines Lessing-Denk$\mathrm{mals}^{32}$ zog seit Anfang der 1860er Jahre langatmige Debatten über die Zweckmäßigkeit einer gemeinsamen Aufstellung aller drei Dichterfiguren vor dem Schauspielhaus nach sich. Der Tenor des Streits blieb weithin vordergrün$\mathrm{dig}^{33}$. Daß man indessen nicht nur um einen prestigeträchtigen Aufstellungsort konkurrierte und eitle Stifterambitionen aufeinanderprallten, legte einer der Berliner Stadträte zumindest für die Schiller-Goethe-Konfiguration offen. Die vehemente Debatte führte er nämlich auf eine Vereinnahmung des Dichterpersonals durch die »politischen Strömungen des Tages« zurück, die Schiller »demokratisch « und Goethe »aristokratisch « konnotierten ${ }^{34}$. Demzufolge hielt sich auch der Monarch demonstrativ zurück, um zu vermeiden, daß »die beiden Dichterfürsten (...) zu politischen Standbildern gestempelt würden, um welche sich die jedesmaligen Partheibewegungen mit ihren politischen Ovationen gruppirten ${ }^{35}$. Traf die Einschätzung des Stadtrats zu, dann favorisierte der Monarch ein »Drei-Statuen-Project«, weil er sich von der Kombination der Figuren einen Neutralisierungseffekt erhoffte: "Nicht Aristokraten oder Demokraten sollen und werden sich dann hier versammeln, sondern alle Diejenigen, die die kulturgeschichtliche Aufgabe unseres Volkes in diesen drei Genien erkennen $(. ..) \ll^{36}$. Damit firmierte zugleich ein ebenso unkonturierter wie parteiübergreifender »Kultur«-Begriff als entpolitisierter Wertbezug für den erstrebten nationalen Konsens ${ }^{37}$.

31 Vgl. ibid. S. 6-8.

32 Vgl. zur Kollision der Initiativen die im folgenden genannten Quellen.

33 Vgl. [BLOEMER,] Drei Dichter-Standbilder in Berlin. Ein Wort zur Einigung. Aus dem Anfange des Jahres 1861, in: [Lessing-Comité,] Aktenstücke und Beläge, die am 6. November 1861 Allerhöchst genehmigte Vereinigung der Standbilder Lessing's, Schiller's und Goethe's vor dem königlichen Schauspielhause zu Berlin betreffend (Vom Anfange 1861 bis 12 . November 1867). Im Auftrage des Lessing-Comités, Berlin ${ }^{2} 1870$, S. 1-5, hier S. 2 und 4. Das Ms. ist zu identifizieren aufgrund des Artikels der NZ vom 15. April 1863, in: ibid. S. 90-96, hier S. 93. Vgl. weiter [An.,] Das Drei-Statuen-Projekt. Als Ms. gedruckt, Berlin 1862, S. 15. Vgl. auch [An.,] Gutachten der Kunstabtheilung des Goethe-Comité über die Aufstellung der drei Standbilder von Schiller, Goethe und Lessing auf dem Gensdarmenmarkte in Berlin, Berlin 1862 und [An.,] Die Modelle zum SchillerDenkmal in Berlin. Ausgestellt im Concert-Saale des Königlichen Schauspielhauses im Juli und August 1862, Berlin 1862.

34 Vgl. Mittheilung des Stadtraths Dr. Woeniger an den Stadtmagistrat vom 23. Mai 1863, in: Communal-Blatt der Haupt- und Residenzstadt Berlin, 2. Juni 1861, S. 166, und wieder in: [Lessing-Comité,] Aktenstücke, S. 31-35, hier S. 32.

35 Ibid. S. 32.

36 Ibid.

37 Vgl. NZ, 15. April 1863 [Adolf STAHR], zit. nach: [Lessing-Comité,] Aktenstücke, S. 9096, hier S. 90. 
Die Einweihung des zuerst fertiggestellten Schiller-Denkmals 1871 prägten dann durchaus noch einmal Züge der landesweiten nachmärzlichen SchillerFeiem, indem neben Vertretern von Bundestag und Bundesrat, mehreren Ministern und städtischen Deputierten auch zahlreiche Studenten und Gesangvereine teilnahmen und der Gendarmenmarkt von »deutschen, preußischen und einzelnen Landesfahnen« umgeben war, die die föderative Qualität der Nation präsent hielten ${ }^{38}$. Demgegenüber unterbrach es die Kontinuität zu den frühen Schiller-Feiern, daß »Damen nach dem Programm» offiziell ausgeschlossen blieben ${ }^{39}$. Am markantesten deutete auf die neuen Bedingungen des SchillerKults nach der Reichseinigung der Umstand hin, daß im ursprünglich genuin bürgerlichen Fest nun der Kaiser die Festszene unmittelbar beobachtete. Erst nachdem Wilhelm $I$. vom Schloß her zusammen mit dem Kronprinzen und weiteren fürstlichen Gästen am Festort eingetroffen war und im gegenüber dem Denkmal am Platz liegenden Gebäude der Seehandlung einen Fensterplatz eingenommen hatte, der ihn zugleich Distanz zum Geschehen wahren ließ, konnte die Feier beginnen. Dem Eingangschoral „Ein' feste Burg«, der das Fest konfessionell verbindlich verortete, folgte nach einigen Reden die Enthüllung, bis das Zeremoniell mit einer dreifachen Umrundung des Denkmals als Akt kollektiver Aneignung des neuen Symbols durch die ihre Fahnen tragenden Chargierten der Studentenverbindungen und mit auf den Kaiser ausgebrachten Hochrufen $\mathrm{schlo}^{40}$.

Stadtsyndikus Duncker erinnerte in seiner Ansprache an den Text der im November 1859 verfaßten Grundsteinlegungsurkunde, die die Dichterehrung mit Schillers Verdiensten um »deutsche Sprache, deutsche Kunst und deutsche Wissenschaft« begründet hatte, bevor sich das Projekt unter dem Eindruck der „Kriegsarbeit, zu welcher von den Werken des Friedens und der Cultur Herrscher und Volk im vorigen Jahre abgerufen wurden ${ }^{41}$, verzögerte. Duncker erwähnte die Reichseinigungskriege eher unemphatisch als Unterbrechung des Denkmalerrichtungsverfahrens und plädierte für eine Schiller-Rezeption jenseits militärischer Assoziationen, in deren Mittelpunkt die Erkenntnis stehen sollte, „daß nur aus den Tiefen des deutschen Geisteslebens deutsches Wesen

38 Anwesend waren auch Generalfeldmarschall von Wrangel, die Minister von Mühler, Handelsminister Itzenplitz, Landwirtschaftsminister von Selchow und neben dreizehn Männergesangvereinen der Stadt und einem Musikkorps eine Abordnung der Studentenverbindung der Königlichen Friedrich-Wilhelm-Universität. Vgl. NPKZ, 11. November 1871, S. I; Germania, 11. November 1871, S. 1; NAZ, 11. November 1871, S. 1; Der Beobachter an der Spree, 12. November 1871, in: [An.] Schiller-Denkmal Berlin 1871, Bd. 1, Berlin 1871 [archivalischer Sammelband], Bl. 4.

${ }^{39}$ Vgl. Berliner Figaro, 12. November 1871, in: [An.,] Schiller-Denkmal Berlin 1871, Bl. 9 Rs.

40 Vgl. NPKZ, Germania, NAZ, wie oben; Berliner Börsenzeitung, 12.November 1871, in: [An.,] Schiller-Denkmal Berlin 1871, Bd. 1, Bl. 6.

41 NPKZ, 11. November 1871 , S. 1. 
und deutsche Kraft sich auferbauen $\aleph^{42}$. Diese Lesart des Schiller-Denkmals nahm sich wie ein Korrektiv zur offiziellen militärischen Siegesinszenierung das Jahres im allgemeinen und besonders der Einweihung des Monarchendenkmals für Friedrich Wilhelm III. fünf Monate zuvor im Lustgarten aus.

Duncker wahrte damit anders als die nachfolgenden Redner eine bemerkenswerte Nähe zur Diktion, die noch die Grundsteinlegungsfeier zum Berliner Schiller-Denkmal 1859 geprägt hatte. Damals nämlich hatte vor allem der Prediger der Neuen Kirche in Berlin, Karl Sydow, die Grundsteinlegung als Zeremoniell einer zum "weltgeschichtlichen Culturvolk berufen[en]« Nation gewertet, dessen »Gemüth« Schiller als mystischer Repräsentant literarisch abgespiegelt hatte: "Solche Denkmäler sind einer Nation wie heilige, schützende Palladien, (...) gleichsam sacramentliche Symbole, nicht bloße Zeichen der Erinnerung an einen großen Todten (...) $\aleph^{43}$. Schiller als Messias und Inkorporation des zur Dominanz bestimmten Kulturvolks, so etwa lautete die wenig bescheidene und gleichwohl prototypische ${ }^{44}$ Parole, die Sydow ausgegeben hatte. Den über die Einzelstaaten verstreuten Deutschen verbürgte Schiller demnach Zusammengehörigkeit als "Volk«, als ethnische ('germanische`), quasi-religiöse geistliche und den hohen inneren ( (Gemüths $\iota$ ) Werten des »Wahren, Guten und Schönen « $^{45}$ verpflichtete sittlich-kulturelle Geistesgemeinschaft. Nicht mehr zur Kompensation fehlender staatlicher Einheit, wie 1859 in der Rede Sydows, sondern als komplementäre Sinndimension neben der Militär- und Machtstaatsidee lohnte auch 1871 bei Duncker noch die Aktivierung des alten Musters der Schiller- und mit ihr assoziierten »kulturellen« Nationsdeutung.

In eklatantem Mißverhältnis zur Festszene 1871 auf dem Gendarmenmarkt und zum Tenor seines Vorredners standen dagegen die Worte Oberbürgermeister Seydels, der die Schiller-Statue in die Obhut der Stadt übernahm und sie paradoxerweise »mitten in das bewegte Leben dieser Stadt ${ }^{46}$ gestellt sah, von dem Polizeikräfte sie zumindest während der Feier hermetisch abschirmten, ohne das Mißverhältnis zwischen exklusiver Inszenierung und inklusivem Deutungspostulat mitzureflektieren. Im übrigen lieferte Seydel genau jene Konnotationen, die Duncker gemieden hatte. Das Jahr der Grundsteinlegung 1859 und damit der Beginn der Neuen Ära firmierte in der Rückschau als "schwankende, zweifelhafte Zeit«, während das Jahr 1871 nun den Inbegriff der "Vollendung" markierte und das Denkmalfest von der ebenso realen wie

${ }^{42}$ Ibid

43 Ibid. S. 4.

44 Vgl. ähnlich etwa Christian Klaus KuNEL, Warum ist Schiller der Dichter der Nation? Rede gehalten in der Versammlung des pegnesischen Blumenordens am 7. November 1859, Nümberg 1859, passim.

45 Adolf SYDOW, Worte bei der Grundsteinlegung zu Schillers Nationaldenkmal, am 10 November 1859 gesprochen, Berlin 1859, S. 8.

46 NPKZ, 11. November 1871, S. 1. 
mystischen Präsenz des Kaisers profitierte, sin dessen starke Hand die gesammelte Kraft des deutschen Volks zu Schutz und Trutz gelegt ist ${ }^{47}$. Seydel betrieb zwar nicht ausschließlich den öffentlichen Kaiserkult, sondern erwähnte ebenso die »berufenen Vertreter des geeinigten deutschen Volks « und die »starken Männer der That«, so daß Parlament und Militär mit dem Kaiser zusammen als Säulen des "Vaterlandes« erschienen. Das Vokabular von Reichs- und Kaiserkult dominierte die Schiller-Deutung aber unübersehbar. In ihrer Gegensätzlichkeit spiegelten die beiden Redebeiträge von 1871 den ambivalenten Gehalt des Schiller-Kults wider, der ordnungspolitisch unpräzise, harmonistische Kultur-Ideen aus der Vorkriegsphase mit machtstaatlich-militärischen Aspirationen seit der Reichsgründung verband.

Die eigentlichen Gründe für die Abriegelung des Denkmalraums lieferte die Neue Preußische Kreuzzeitung nach, die es für angemessen hielt, daß die Feiergemeinde zwischen sich und die übrige Öffentlichkeit Barrikaden setzte: »die ärgerlichen Erfahrungen vor 12 Jahren bei der Grundsteinlegung " hatten $z u$ "strengsten Maßregeln zur Aufrechterhaltung der Ordnung" veranlaßt ${ }^{48}$. Gemeint waren die Vorkommnisse anläßlich der Berliner Grundsteinlegungsfeier am 10. November 1859, als die Behörden dem Schiller-Komitee aus Sorge vor öffentlichen Unruhen und einer massiven, emphatischen "Einheits«Propaganda einen großen Festumzug, wie ihn liberale und demokratisch gesinnte Handwerkerinnungen durchzuführen wünschten, untersagt und nur geschlossene Veranstaltungen genehmigt hatten ${ }^{49} . \mathrm{DaB}$ die Grundsteinlegungsfeier ihrerseits unter weitgehender Aussperrung der Öffentlichkeit stattgefunden hatte, bevor ihr abendliche Ausschreitungen folgten, als die ausgeschlossenen Handwerker und Arbeiter demonstrativ mit roten Fahnen auftauchten und den argwöhnischen Behörden zufolge den Ort des Schiller- mit dem des Revolutionsgedenkens verquickten ${ }^{50}$, war der Kreuzzeitung noch 1871 gegenwärtig. Umso mehr löste Genugtuung aus, daß es 1871 nicht mehr gelang, Schiller gleichermaßen für die geeinte Nation wie für Demokratie- und Freiheitswerte in Beschlag zu nehmen, sondern ihn zum Heroen einer distinkten bürgerlichen Gemeinschaft zu stilisieren ${ }^{51}$.

Emphatisch würdigte hingegen der Herausgeber der Zeitschrift Unsere Zeit Rudolf Gottschall die Denkmalerrichtung, die er mit der Grundsteinlegungsfeier nun nicht verglich, um sie zu kritisieren, sondern um eine Entwicklung vom deutschen »Volk der Denker und Dichter« zum »siegreichen Volk der

47 Ibid

48 Vgl. NPKZ, 11. November 1871, S. 1.

49 Vgl. NOLTENIUS, Schiller als Führer und Heiland, S. 240-248.

50 Vl. ibid. S. 248.

51 Berliner Figaro, 12. November 1871, in: [An.,] Schiller-Denkmal Berlin 1871, Bd. 1, Bl. 9 Rs. 
That« zu diagnostizieren ${ }^{52}$ : Das vergeistigte »Dichter- und Denker-Volk« nämlich schien den »nationalen Schillercultus« mit einer problematischen "stillschweigende[n] Verurtheilung zu politischer Ohnmacht als der selbstverständliche[n] Folge (...) träumerische[r] Gemüthsneigung« erkauft zu haben. Im personalen Kultus spiegelte sich damit vor 1871 die Disposition der deutschen Nation zur kompensatorischen, die nationale Einheit entbehrenden Verehrung geistiger Größe wider und Gottschall mutmaßte hämischen Konsens konkurrierender Nationen zu solcher Gestimmtheit: »Man ließ das Volk von Denkern und Dichtern gewähren, welches vielleicht den philosophischen Schwerpunkt des Weltalls, aber nicht die Waage des europäischen Gleichgewichts ins Schwanken zu bringen vermag ${ }^{53}$. Die Kriegszäsur von 1870/71 förderte demgegenüber den Wandel der Nation von der »geistige[n]« zur "politische[n] Großmacht«, potenzierte den »Geist« zur »Macht«. Indem er die Nation im »Reich des Friedens und der Freiheit, der Kunst und Wissenschaft ${ }^{54}$ angekommen sah, mochte Gottschall in der Nation als Kriegsgeburt, an die Schiller nun neuerdings auch erinnerte, keine Militarisierung erkennen.

Der Neue Socialdemokrat hingegen spießte das hermetische Prozedere des Schiller-Festes von 1871 auf $^{55}$ und bekundete Dissens, indem er statt vom tatsächlich errichteten von einem imaginären Schiller-Denkmal redete, das authentisch im "Volk « verwurzelt sein und zumindest vage eine demokratische Dimension der Nation wachhalten müsse. An die Stelle des Einweihungsberichts trat ein Artikel, der das alternative Deutungsmuster als Teil einer linken Geschichtstheorie skizzierte ${ }^{56}$. Kämpfte Schillers vorrevolutionäres Schweizer Volk noch gegen adlige Tyrannen, so entsprach dem jetzt das Aufbegehren des »unterdrückten Arbeitervolks« gegen die postrevolutionäre, bürgerliche »Tyrannei des Kapitals.« Der Emanzipationsaufruf, in den die einschlägige historische Aktualisierung des Schillerdramas mündete, zielte zwar eher auf die "Proletarier aller Länder«, er galt indessen zunächst und als Voraussetzung zur internationalen Solidarisierung gezielt der auf ein striktes Egalitätsgebot verpflichteten deutschen Nation ${ }^{57}$. Zum Symbolwiderspruch war die sozialdemokratische Linke indessen anders als noch 1859 nur rhetorisch-semantisch, nicht aber konkret-praktisch in der Lage, denn rote Fahnen tauchten im Festbild der Denkmaleinweihung 1871 nicht einmal am Rande auf.

Vgl. Rudolf GoTTSCHALL, Schiller und seine Gegner, in: Unsere Zeit. Deutsche Revue der Gegenwart. Monatsschrift zum Conversationslexikon, N.F. 7. Jahrgang, 2. Hälfte, Leipzig 1871, S. 721-737, hier S. 721 .

53 Ibid

54 Ibid

${ }_{55}$ Neuer Socialdemokrat, 12. November 1871, S. 4: "(...) das Volk, dem jener Todte so nahe steht, war nicht geladen.

${ }^{56}$ Ibid. 12. November 1871, S. 1.

57 Vgl. ibid. 
Die Deutungsmuster, die in der Duncker-Rede von 1871 angeklungen waren, bewiesen ungeachtet einer dominanten Inkorporierung in den Ritus der monarchischen Nation Beharrungskraft. Als die Berliner Schiller-Statue anläßlich der Feierlichkeiten zu seinem 100. Todestag im Mai 1905 erneut in das öffentliche Ritual eingebunden wurde, indem dort Kränze niedergelegt und musikalische Aufführungen geboten wurden ${ }^{58}$, nahm die liberale Vossische Zeitung zustimmend zur Kenntnis, daß das »militärisch erzogene Volk« hier »einmal nicht einen siegreichen Heerführer, nicht einen erfolgreichen Staatsmann, sondern ein Mitglied jener Republik, in der die Bahnbrecher der Kultur den Ton angeben «, ehrte ${ }^{59}$. Die Attraktivität des Schiller-Kults bestand gerade darin, daß er ein "freiheitliches Volksbewußtsein« beförderte, das dem reaktionären »Geist (...), der schon nur zu lange in deutschen Landen auf Gesetzgebung und Verwaltung lastet ${ }^{60}$, entgegenstand. Die Figur behielt eine ambivalente Wertigkeit, indem sie auf die Assoziation des Machtstaats nicht festzulegen war, sondern die Idee von Freiheitspostulaten präsent halten konnte.

Ungleich weniger politisierend gestaltete sich die Rezeptionsgeschichte des Berliner Goethe-Denkmals, das Anfang Juni 1880 im Tiergarten in südlicher Richtung vom Brandenburger Tor erneut in Gegenwart des Kaisers wie des Kronprinzen Friedrich Wilhelm eingeweiht wurde ${ }^{61}$. Vergleichbar zum Fest von 1871 waren Minister und zahlreiche Vertreter akademischer und anderer Bildungs- und Kulturinstitutionen erschienen ${ }^{62}$. Einheitsvision und sprachlichgeistig vermittelte, kulturelle Missionsidee blieben in enger Nähe zum Schiller-Kult die Quintessenz der über die Goethe-Figur assoziierten Nation ${ }^{63}$. Dennoch erschien die öffentliche Rezeption einigermaßen verhalten ${ }^{64}$, wenn nicht ohnehin die Germania konfessionell-religiöse Ressentiments gegen den mutmaßlichen $»$ Heiden $«$ vorbrachte ${ }^{65}$.

Vgl. Programm der Berliner Schillerfeier am 9. Mai 1905, 121/2 mittags, am Schillerdenkmal, LAB A Rep. 000-02-01 Nr. 1621 [up].

${ }^{61}$ Vgl. zum Folgenden NPKZ, 3. Juni 1880, S. 1; VZ, 2. Juni 1880, S. 2; Berliner Tageblatt, 2. Juni 1880, S. 1; Tribüne, 3. Juni 1880, in: [Adolph ScHULZE,] Festzeitung zur Feier der Enthuellung des Goethe-Denkmals im Thiergarten zu Berlin am 2. Juni 1880, Berlin 1880, S. 22; [An.,] Das Goethe-Denkmal im Thiergarten zu Berlin, Berlin 1880

${ }^{62}$ Anwesend waren u.a. Kriegsminister Georg von Kameke, Admiral Albrecht von Stosch, Stadträte und Stadtverordnete samt Oberbürgermeister von Forckenbeck, Vertreter der Kunstakademie, der Universität, der Technischen Hochschule, der Gewerbe-Akademie sowie Journalisten. Vgl. NPKZ, 3. Juni 1880, S. 1.

$63 \mathrm{Vgl}$. ibid. 4. Juni 1880, S. 2.

${ }^{64}$ Vgl. VZ, 2. Juni 1880, S. 2; [A. E. KNOPF, Das Goethe-Denkmal im Thiergarten zu Berlin, enthüllt am 2. Juni 1880, Berlin 1880, hier S. 6-11; [SCHULZE,] Festzeitung, S. 4-16; Otto BRAHM, Goethe und Berlin. Festschrift zur Enthüllung des Berliner GoetheDenkmals, Berlin 1880 , hier v.a. S. 3f., 7, 12, 14.

${ }^{65}$ Germania, 3. Juni 1880 , B., S. 3. 
Die zögerlichen Voten waren Symptome für den raschen Verschleiß von Sinnstiftungspotentialen, die die Figur im Vorfeld der Reichsgründung in einem der Schiller-Figur durchaus vergleichbaren Maße besessen hatte. Noch in der Frühphase der Denkmalerrichtung 1860 hatte etwa der Kirchenhistoriker Ferdinand Piper in Goethes Namen den Anspruch auf die Konstituierung einer einheitlichen deutschen Nation »auf rein geistige[m] Gebiet« angemeldet $^{66}$. Goethe exemplifizierte mithin über das »engere preußische Interesse hinaus" den Willen der »Deutschen« zur »Nation (...) ungeachtet aller Schranken der Verfassung, der Stände, der Bildung ${ }^{67}$. Über die lange Verzögerung der Denkmalschöpfung, die aus den Kollisionen mit dem Schiller-Projekt resultierte, verflachte das einmal etablierte Deutungsmuster. Unter »Kosmopolitismus«-Verdacht geraten, schien sich Goethe immer weniger zum Kronzeugen für den nationalen Gründungs- und Erhebungsmythos des Reichs zu eignen ${ }^{68}$.

Mitte Oktober 1890 schließlich folgte als letzte der ursprünglich als Ensemble geplanten Denkmäler die Lessing-Statue im südlichen Tiergarten an der Lennéstraße ${ }^{69}$. Mit dem Empfang des den Kaiser vertretenden Prinzen Friedrich Leopold, Hochrufen auf den Kaiser und abschließender Inspektion des Monuments perpetuierte das Festprogramm routiniert gängige Schemata; das galt auch für das am Abend des gleichen Tages anberaumte große Bankett im Hotel Kaiserhof mit über hundert - wie die Vossische Zeitung nicht ohne kritischen Unterton ausdrücklich betonte - ausschließlich männlichen Teilnehmern $^{70}$.

Der Direktor des Weimarer Goethe-Archivs Erich Schmidt sah Lessings Bild bereits als inhärenten Bestandteil der offiziellen Ikonographie der "via triumphalis« Unter den Linden, indem es nun mit der Relieffigur des Literaten im Sockelprogramm des Friedrich II.-Monuments korrespondierte, wo sie neben den »Krieger[n] und Staatsmänner[n]« die »Aufklärung« und den »aufsteigenden Zukunftsstaat« repräsentierte ${ }^{71}$. Daß man mit einer monarchienahen Spra-

66

67

${ }^{68}$ Vgl. u.a. NPKZ, 29. August 1899, S. 1 [Gotthold BOTTTCHER]: „Unser nationales Empfinden im politischen Sinne, (...) findet bei Goethe keinen Anknüpfungspunkt. (...) Wir sind über den Kosmopolitismus hinausgewachsen, und sind weit entfernt, in ihm das Kennzeichen eines großen Geistes zu sehen."

69 Anwesend waren neben dem Oberbürgermeister von Berlin von Forckenbeck, Bürgermeister Duncker und mehreren Stadtverordneten die Mitglieder des Senats der Akademie, Berliner Künstler und Wissenschaftler und schließlich Staatsminister von GoBler, der Staatssekretär des Reichsamtes des Inneren von Boetticher, Finanzminister Johannes Miquel sowie Polizeipräsident von Richthofen. Vgl. VZ, 14. Oktober 1890, S. 1-2, hier S. 1; Deutscher Reichs-Anzeiger, 14. Oktober 1890, LAB A Rep. 000-02-01 Nr. 1622 [up]; NZ, 14. Oktober 1890 (A.), S. 1-2, hier S. 1.

7 Vgl. VZ, 14. Oktober 1890, S. 1-2, hier S. 1; NZ, 14. Oktober 1890 (A.), S. 1. 
che, die auch die übrigen Reden dominierte, vor allem der Anwesenheit des Prinzen Rechnung trug, wurde anläßlich des exklusiv bürgerlichen abendlichen Festbanketts erkennbar, als entsprechende Konnotierungen weithin ausfielen. Hier nun wurde die gebildete Nation thematisiert und die Vereinigung aller »Deutschen (...) zu einem neuen, großen Lessingkomitee, ohne Statuten, ohne Präsidenten, Schriftführer« imaginiert, die Lessings Toleranz-Gedanken aus dem "Nathan « wachhielten ${ }^{72}$. Die bildungsbürgerliche Lessing-Emphase kulminierte hier nun gerade nicht in der Idee monarchischer Überformung, sondern in der Fiktion von der Nation als einer Art hierarchiefreien Komitees.

Liberale Pressekommentare griffen in der Regel Sinnzuweisungen aus beiden Veranstaltungen auf. So verortete die National-Zeitung Lessing einerseits auf der Seite des "preußische[n] (...) Staates«, befürwortete aber genauso die komplette Durchdringung "alle[r] Schichten und alle[r] Gebiete unsers Volksthums « mit seinem Denken ${ }^{73}$. Demgegenüber zeigte sich die Kreuz-Zeitung nicht bereit, in die süberschwänglichen Lobpreisungen einzustimmen, die der Liberalismus in allen Schattirungen bei jeder Gelegenheit an den Namen Lessings knüpft«, zumal eine absichtsvolle Überpointierung seiner »Stellung als politischer Bannerträger" und letztlich »oberflächliche Tendenzmacherei« geargwöhnt wurden ${ }^{74}$. Für kritikwürdig befand die Kreuz-Zeitung unterdessen Lessings Credo zugunsten einer areligiösen "Sittlichkeit«. Maximal eine unpo-

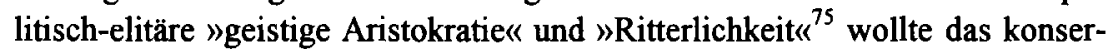
vative Blatt statt dessen in ihm verkörpert sehen. Ähnlich unterstellte auch die Germania, daß die Lessing-Figur von den Liberalen als »Büttel für die sogenannte Gedanken- und Gewissensfreiheit« unredlich vereinnahmt worden $\mathrm{sei}^{76}$. Daß es insbesondere die "jüdisch-liberale Presse« wie Rudolf Mosses Berliner Tageblatt sei, die in Lessing den Protagonisten der freiheitlich-emanzipatorischen Nationsidee feierte, wurde mit spitzer antijüdischer Polemik registriert. Hinter dem Inklusions- und Aufklärungspostulat machte die Germania daher Ansätze zu einem »jüdisch-liberalen« Sonderbewußtsein aus, das sich auf Kosten der »abgeschmackten christlichen Religion « zu profilieren versuchte $^{77}$. Die als solche diffamierten »jüdischen « Lessing-Deuter glaubte sie als "Christusfeinde«, "Verächter jedes Autoritätsglaubens« und am Ende "Stifter einer neuen >Religion « $/$ entlarven zu müssen ${ }^{78}$. Der Kommentar geriet so zum angespannten Rückzugsgefecht angesichts befürchteter Aufweichungen bisheriger Deutungsmonopole durch politische Formationen, deren Teil-

76 Vgl. Germania, 15. Oktober 1890, S. 1.

77 Vgl. ibid.

${ }^{78}$ Germania, 16. Oktober 1890, S. 1. 
habe am nationalen Sinnstiftungsdiskurs nicht erwünscht war. Die Anlagerung des antisemitischen Exklusionsdiskurses blieb ein Spezifikum der konservativen Lessing-Rezeption, der den Zuspruch zum Denkmal massiv mindern mußte ${ }^{79}$.

\subsection{Deutungsspielräume}

Nicht ganz so flächendeckend wie in Paris, aber durchaus mit beträchtlicher Häufigkeit prägten auch das Berliner Denkmalareal die Literaten- und Künstlerdenkmäler. ${ }^{80}$ Die Assoziationsbandbreite, die sich von diesen Denkmälern her auf die Nation erschloß, blieb dabei denkbar groß, schwankte durchaus zwischen Inklusion und Transnationalismus zum einen und mindestens kulturmissionarischer Arroganz und machtstaatlicher Fixierung zum anderen.

$\mathrm{Da} ß$ der Dichterkult indessen auch Nationsdeutungen Vorschub leistete, die ohne schablonenhafte Fixierungen auf Selbstbilder auskamen, deutete sich im Zusammenhang mit der Feier eines Denkmals für Adalbert von Chamisso auf dem Monbijouplatz Ende Oktober 1888 an. Wenn zunächst betont wurde, daß mit Chamisso der "Sohn jener Nation, die unser Todtfeind war" auf dem Wege der kulturellen Aneignung gleichsam an die deutsche Nation übergegangen war, lag darin gleichermaßen die Idee des Triumphs wie der Öffnung gegenüber der französischen Kultur ${ }^{81}$.

Diesen Tenor bewahrte vor allem die liberale Presse. Im Berliner Tageblatt wurde im Zeichen der Chamisso-Figur auf die Beschwichtigung "politische[r]

79 Um 1899 erhielten die Dichter der Befreiungskriege Uhland, Kleist, Rückert, Arndt, Körner und von Schenckendorff Hermen im Viktoriapark in Kreuzberg. Den spärlichen Dokumenten zufolge handelte es sich um eine Initiative des Magistrats von Berlin, vgl. Schreiben des Kultusministers an den König vom 19. Oktober 1898, GStA PK I. HA Rep. $89 \mathrm{Nr}$. 20837, Bl. 197. Gedacht war ebenso an die nationalpolitische Reaktivierung des zu Jahrhundertbeginn in Erinnerung an die Befreiungskriege errichteten Kreuzbergdenkmals wie auch an seine Popularisierung und öffentliche Musealisierung. Bereits 1878 war das Kreuzbergdenkmal aufgestockt worden, um es besser sichtbar zu machen. Später wurde die Häuserhöhe im Umfeld des Monuments reguliert und ab den späten 1880er Jahren der angrenzende Park mit Dichterbüsten ausgestattet, die das pädagogische Programm der Ruhmeshalle im Zeughaus nun in den Außenraum tragen sollten. Vgl. [An.,] Das NationalDenkmal auf dem Kreuzberge, S. 15-16; Denkschrift betreffend die Hebung des Denkmals auf dem Kreuzberge in Berlin im Jahre 1878, GStA PK I. HA Rep. 89 Nr. 20842, Bl. 99.

${ }^{80} \mathrm{Vgl}$. allgemein Ernst SchULTZE, Wie wir unsere großen Dichter ehren sollten. Ein Wort über Dichter-Denkmäler und anderes, Leipzig 1902; Richard SIER, Deutschlands GeistesHelden. Ehren-Denkmäler unserer hervorragenden Führer auf geistigem Gebiet in Wort und Bild. Auf Grund geschichtlicher Unterlagen und authentischer Quellen, Berlin 1904; Emil NAUMANN, Deutschlands musikalische Helden in ihrer Rückwirkung auf die Nation. Vortrag, gehalten am 15. Februar 1873 im Wissenschaftlichen Verein zu Berlin, Berlin 1873 .

81 Vgl. Berliner Tageblatt, 29. Oktober 1888, LAB A Rep. 000-02-01 Nr. 1634, Bl. 178. 
Spannungen zwischen Deutschland und Frankreich « spekuliert und die transnationale »Humanität« des Grenzgängers zwischen Frankreich und Deutschland hervorgehoben ${ }^{82}$. Zugleich betonte man hier, daß das Denkmal »in (...) der Hauptstadt eines mächtigen geeinten Reiches (...) unter einem freien Volke, von dessen Großthaten und errungenen politischen Freiheiten er [i.e. Chamisso, H.R.] sich nichts hat erträumen lassen ${ }^{83}$, entstanden war. Damit galt die Feier mindestens ebenso sehr dem Dichter wie dem »Reich«, dessen Konstituierung sich nun aber nicht primär als monarchisch-machtstaatliches Produkt, sondern als fulminanter Endpunkt eines kollektiven »Volks«-Handelns ausnahm und mit dem ausdrücklichen Bekenntnis zu "politischen Freiheits《Werten vereinbar schien. Damit kam im unmittelbaren Kontext der ChamissoFigur zugleich ein tendenziell alternativer, nämlich statt des Monarchen und des Militärs das »Volk« zentral veranschlagender Reichsgründungsmythos zur Sprache.

Durchaus ähnliche Konnotierungen tauchten im Mai 1910 anläßlich der Einweihung des Denkmals für Theodor Fontane im Tiergarten wieder auf ${ }^{84}$. Die Festrede des Komiteevorsitzenden und Germanisten Konrad Burdach stilisierte Fontane zum Exempel der Inklusion: Er stand für die vorbildliche Integration der "französischen Emigranten«, von denen er abstammte, win den preußischen Staat«, dem er sich ebenso durch »Bürgertugend« anglich, wie er ihn bereicherte. Fontane stand für den Prozeß der Ausprägung »deutscher« durch die Amalgamierung europäischer Kultur:

Dieser (...) Sprößling alten tapferen Hugenottenblutes hat durch sein Schaffen das Märchen widerlegt von der Erbfeindschaft der französischen und der deutschen Nation und das jüngere Märchen von der Gegnerschaft englischer und deutscher Kultur. Sein bestes dankt er der Mischung deutscher, englischer, französischer Bildung ${ }^{85}$.

Damit warben die Denkmalstifter ebenso für einen transnationalen Kulturbegriff wie für eine Aufhebung stereotyper Feindbilder und eine nationale Selbstdefinition, die ohne Exklusion und Diffamierung auskommen sollte. Die Nationen stellten sich allesamt als »soziale Organism[en]« mit »sozialen Klassen« dar, und das einzige Spezifikum, das für die deutsche Nation reklamiert wurde, bezog sich auf einen besonders dringlichen Bedarf an einem wversöhnenden Ausgleich konfessioneller und sozialer Gegensätze« und also an Homogenisierung im Inneren. Fontane versuchte sie den Denkmalstiftern zufolge bereits zu leisten, indem er die »siegreich heimkehrenden Berliner Truppen«

${ }^{82}$ Ibid. 27. Oktober 1888, LAB A Rep. 000-02-01 Nr. 1634, Bl. 177.

${ }^{83}$ Ibid. 29. Oktober 1888, ibid.

${ }^{84}$ Vgl. Mitteilung aus dem Geheimen Zivilkabinett an den Innen- und den Finanzminister, 12. November 1909, GStA PK I. HA Rep. 77 Tit. 151 Nr. 15 Fasz. 60, Bl. 4; NZ, 7. Mai 1910 (A.), S. 3; VZ, 7. Mai 1910 (A.), S. 3; Berliner Tageblatt, 7. Mai 1910, LAB A Rep. 000-02-01 Nr. 1636, Bl. 111.

85 Ibid. 
literarisch visualisierte und »Kaiser Wilhelm und Bismarck« feierte ${ }^{86}$. Militärische und machtstaatliche Reichsgründung und ein den Kaiser und seinen Kanzler fixierender Heroenkult dominierten so unversehens wieder das deutsche Selbstbild, blieben aber anknüpfungsfähig an eine europäische Kulturdimension.

Jenseits der harmonistischen Sinnstiftungsentwürfe lag demgegenüber die Programmatik zum am 1. Oktober 1903 am Nordrand der Tiergartenstraße eingeweihten Denkmal für Richard Wagner ${ }^{87}$, obschon hier ein ausgesprochen internationales Publikum vor dem Monument zusammenkam. Daß damit noch keine kosmopolitische Programmatik garantiert war, hatten bereits Verlautbarungen des Denkmalkomitees gezeigt, das sich zum Ziel setzte, »jede der anderen Nationen die Überlegenheit der deutschen musikalischen Bildung« erkennen zu lassen und insofern nur einen geweiteten Präsentationsrahmen für die Demonstration wausserordentliche[r] Cultur-Mission« der deutschen Nation suchte $^{88}$. Der Subskriptionsaufruf dokumentierte den mit dem Wagner-Kult verbundenen Dominanzanspruch, indem er den Komponisten als »Kämpfer für Deutschlands Ruhm und Größe« apostrophierte und weniger in schöngeistiger als in militaristischer Manier schon seinen "Sieg (...) über alle Nationen der Welt « proklamierte ${ }^{89}$. Die knappen Reden taten ein übriges, den kulturellen Führungsanspruch der Nation in Gestalt ihres Exponenten Wagner einzufordern $^{90}$.

In der Presse überwog die Kritik an Trivialität von Form und Aussage des Denkmals ${ }^{91}$. Als Motiv derartiger Verwerfungen wurde die Verquickung von holistischem Kunstverständnis und mythisch-emotionalisierter Volksidee erkennbar: Wagners Genius, so begründete man den Kult, hatte darin bestanden, Affekt und Ratio, Alltäglichkeit und Transzendenz, Moderne und archaische "Urkraft" als Quintessenz heterogener Befindlichkeiten der Nation als "Volk« zum Ausdruck zu bringen ${ }^{92}$. Dem bildhauerischen Werk war nun dem Pressevotum zufolge dieser Transfer nicht gelungen.

86 Vgl. ibid.

87 Vgl. auch zum Folgenden NPKZ, 1. Oktober 1903 (A.), S. 2, NZ, 1. Oktober 1903 (A.), S. 1; Berliner Tageblatt, 1. Oktober 1903, LAB A Rep. 000-02-01 Nr. 1635 Bl. 257; VZ, 2. Oktober 1903 (2. B.), S. 1.

$88 \mathrm{Vgl}$. Aufruf des Wagner-Komitees zu einem Internationalen Musikfest in Berlin vom November 1902, GStA PK I. HA Rep. 89 Nr. 20838, Bl. 118-126, hier Bl. 118-120.

91 Vgl. ibid. und ibid. 1. Oktober 1903 (1. B.), S. 1; NZ, 2. Oktober 1903 (M.), S. 1-2, hier S. 1.

92 Vgl. NZ ibid.: "Durch alle Himmel und Höllen unserer Seelen ist er geschritten, (...) die Gottesliebe (...), die Freude am Einfachen (...) und die grüblerische Zergliederung des (...) modemen Empfindens, die Hinneigung zur elementaren Urkraft der Natur (...), alles hat er in sich aufgenommen." 
Symptomatischer als diese Kritik blieb jedoch die in der Schilderung von Wagners Genius enthaltene Diagnose des Zustands einer Nation, die in der Kunst ihre elementare Zerrissenheit und Größensehnsucht verhandelt und gerne auch pathetisch aufbereitet sehen wollte. Sie erwartete die Ästhetisierung ihres »Wesens « als "Volk« und glaubte sie in Wagnerscher Tonalität und mythischer Erzählung als "Selbstbegegnung ${ }^{93}$ des "Volkes« gefunden zu haben. Damit blieb die im Kontext der Wagner-Figur assoziierte Nationsidee mystisch-innerlich und so stark auf ästhetische Widerspiegelungen fixiert, daß jeder Rekurs auf den realpolitischen Zustand dieses "Volks« weit außerhalb des Betrachtungshorizonts blieb. Sowohl die Vossische ${ }^{94}$ als auch der Vorwärts gingen ohnedies zur Mystik des Wagner-Kults auf Distanz ${ }^{95}$. Indessen wurde keines der Komponistendenkmäler, die später noch in Berlin entstanden, mehr mit derart voluminösen Sinnkonstruktionen befrachtet ${ }^{96}$.

Weniger ein vager »Volks «- als ein konkreter Preußen- und Reichsbegriff wurde mit dem Denkmal für Heinrich von Treitschke zum Thema, das Anfang Oktober $1909 \mathrm{im}$ Vorgarten der Universität in Anwesenheit diverser Minister und städtischer wie universitärer Vertreter für den renommierten Historiker der kleindeutschen Schule enthüllt wurde ${ }^{97}$. Der Generaldirektor des Königlichen Staatsarchivs Reinhold Koser hob zum Zeichen monarchischer Deutungsnähe die finanzielle Beteiligung des Kaisers am Denkmal besonders hervor, bevor er Treitschke als letzten Vertreter einer aus der "politische[n] Ueberzeugung" von der gleichsam notwendigen preußischen Dominanz in der Nation gespeisten Historiographie würdigte ${ }^{98}$. Insofern lieferte der Neo-Rankeaner Koser hier zwar den Abgesang auf die borussisch-nationalliberale Historiographie,

93 Lothar GALL, Gegenwart und Mythos in Richard Wagners »Ring «, in: DERS., Bürgertum, liberale Bewegung und Nation. Ausgewählte Aufsätze, München 1996, S. 362-372, hier S. 366.

94 Die Vossische zog sich auf eine rein ästhetische Beurteilung des Monuments zurück; vgl. VZ, 1. Oktober 1903 (Forsetzung der 1. B.), S. 4-5, hier S. 4.

95 Vgl. Vorwärts, 2. Oktober 1903 (2. B.), S. 1.

96 Vgl. zum Denkmal Anfang Juli 1904 für Haydn, Mozart und Beethoven nahe dem Kemperplatz NPKZ, 2. Juli 1904, S. 2; Aufruf zur Errichtung eines gemeinsamen Denkmals für Haydn, Mozart und Beethoven in Berlin vom April 1891, GStA PK I. HA Rep. 89 Nr. 20837, Bl. 22; Bekanntmachung vom 27. Juni 1904, GStA PK I. HA Rep, 89 Nr. 20839, Bl. 21. Unspektakulär blieb auch die Aufstellung und Einweihung einer Büste für den Komponisten Lortzing nahe der Rousseau-Insel im Tiergarten Ende Oktober 1906. Vgl. Berliner Tageblatt, 29. Oktober 1906, LAB A Rep. 000-02-01 Nr. 1636, Bl. 70; Aufruf zur Errichtung eines Lortzing-Denkmals in Berlin, VZ, 18. Oktober 1901, LAB A Rep. 000-02-01 Nr. 1635, Bl. 207 Rs.

97 Vgl. NPKZ, 9. Oktober 1909 (A.), S. 2; VZ, 9. Oktober 1907 (A.), S. 4; NZ, 9. Oktober 1909 (A.), S. 3.

98 Vgl. NPKZ, 9. Oktober 1909 (A.), S. 2. Daß hier erstmals der rigiden Germanisierungsidealen verpflichtete radikalnationalistische Agitationsverband des Deutschen Ostmarkenvereins in der Festszene auftauchte, blieb allerdings Episode. Vgl. auch NPKZ, 12. Oktober 1909 (B.), S. 2. 
blieb der national-kleindeutschen Perspektive Treitschkes dessenungeachtet aber verpflichtet. Treitschke wurde der Festversammlung aber nun nicht nur als gefeierter Apologet eines kleindeutsch-preußischen und -protestantischen Nationalismus anempfohlen, er stand auch für einen wehrhaften »Patriotismus«, der dem »Vaterlandsgedanken« und dem »Staat « höchste Priorität einräumte. $\mathrm{Da} B$ die Reichsnation auf Außenverteidigung angewiesen sein würde, klang in den vage assoziierten Bedrohungsszenarien an.

Übergangen wurde hingegen, daß die "Sorge ums Vaterland« Treitschke durchaus zu antidemokratischen, antisozialistischen und nicht zuletzt antisemitischen Deutungsmustern und also einem zunehmend nach innen wie nach unten exklusiven Diskurs über die Nation Anlaß geboten hatte ${ }^{99}$. Eine überwiegende Mehrheit der Presse nahm Treitschkes Wandel vom unitarischen Liberalismus zum ethnisch exklusiven Konservativismus und eine entsprechende Revision seiner Nationsbilder nicht zur Kenntnis, noch sah sie sich zur Kritik an seinen antisemitischen Anwandlungen veranlaßt ${ }^{100}$. Damit war die Ehrung des profilierten Exponenten jener kleindeutschen Historiographietradition in Deutschland konsensfähig, die schon vor der Reichsgründung die preuBische Prädestination zur Dominanz im künftigen Nationalstaat zum Programm erhoben hatte und sich insofern in die offiziöse Dogmatik der Monarchen- und Militärdenkmäler aus preußischer Sicht nur allzugut einfuigte. Der Deutungsspielraum, den das Kulturpersonal in der Berliner Denkmallandschaft abdeckte, blieb damit erheblich weit, hielt inklusive wie exklusive, transnationale wie Reichs- oder Preußen-zentrierte nationale Assoziationen bereit.

\section{London: Nation und dissoziierte $»$ Kultur»}

Auch im Umfeld der seit Mitte der 1870er Jahre entstandenen Denkmäler für Shakespeare, Byron, Carlyle und Burns entfaltete sich in London ein eher mäandernder als konziser nationaler Diskurs, der weniger um ein Konzept verbindlicher nationaler Kultur als um außen-, vor allem aber sozialpolitische Konnotierungen der Nationsidee kreiste. Volksnähe und soziale Homogenisierung, Konstitutionalismus und Freiheitsrechte, radikale Partizipation oder sozialdefensiv-aristokratische Führung und schließlich die Differenzbestimmung im multinationalen Königreich bildete das breite Themenspektrum, das sich

99

Vgl. zu Treitschkes Rolle im Berliner Antisemitismusstreit Marianne AWERBUCH, Heinrich von Treitschke, in: ERBE (Hg.), Berlinische Lebensbilder, Bd. 4, S. 209-230, hier S. 222-225.

${ }^{100}$ Vgl. VZ, 9. Oktober 1907 (A.), S. 4; NZ, 9. Oktober 1909 (A.), S. 2. 
von den Protagonisten einer folglich höchst unterschiedlich identifizierten Kultur her auf die nationale Ordnung schlaglichtartig je neu eröffnete.

Programmatisch marginal blieb zunächst ein Anfang Juli 1874 auf dem zentral gelegenen Leicester Square plaziertes Denkmal für William Shakespeare. Zum Bild des Zerfalls hatte dort zuvor lange Jahre die völlige Vernachlässigung eines 1748 errichteten Reiterdenkmals von George I. gezählt, das Mitte des 19. Jahrhunderts vorübergehend vergraben, dann in den 1860er Jahren in unrestauriertem, halbzerfallenem Zustand wieder aufgestellt, mehrmals zum Opfer öffentlichen, Einschätzungen der Presse zufolge allerdings unpolitischen Vandalismus' geworden war ${ }^{101}$. Im Winter 1866 hatte sich der Anblick des Reiterdenkmals zum Skandal ausgewachsen, als Unbekannte das Monument über Nacht bemalten und verkleideten und damit die ohnedies beeinträchtigte Aura des Monarchendenkmals in einem Akt der ästhetischen Perversion endgültig zerstörten ${ }^{102}$. Seit Anfang der 1870er Jahre war Leicester Square nun auf Betreiben eines finanzkräftigen Privatiers hin ohne die Statue Georges I. wiederhergerichtet worden, so da $B$ das neue Monument für den "national poet« zugleich die Krönung eines Sanierungsvorhabens darstellte ${ }^{103}$. Im Zentrum der Reden am 3. Juli 1874 stand daher auch das Argument, daß die monumentale Neugestaltung des Platzes als überfallige Wiedergutmachung eines »national disgrace $\ll$ zu gelten hatte ${ }^{104}$. Das Shakespeare-Monument wirkte gleichermaBen als dekorativer Zugewinn wie als Signum gelungener Regeneration. Offentliche Deutungen der Shakespeare-Figur blieben damit weithin aus, während die Programmatik des "public place« als eines der Rekreation des sozial nicht weiter differenzierten »people« vorbehaltenen öffentlichen Raums dominierte $^{105}$.

Mit vorausgehenden Plänen für ein Shakespeare-Denkmal, die kurz nach der Jahrhundertmitte jahrelang kursiert waren, hatte das letztlich realisierte Projekt einerseits wenig gemein; andererseits setzte es durchaus eine quasi-plebejische, demokratisierende Deutungstradition fort, die sich längst während der zweiten Jahrhunderthälfte zu entwickeln begonnen hatte.

Bereits Anfang der 1850er Jahre war ein entsprechender Denkmalvorschlag öffentlich unterbreitet worden, der auf Shakespeare als den Poeten ausgerichtet war, dessen Genie der englischen Sprache weltweite Bewunderung gesichert

${ }^{101} \mathrm{Vgl}$. The Statue in Leicester Square, Sitzung des HoC, 13. Juli 1863, in: Hansard $3^{\text {rd }}$ s., 172 (1863), Sp. 659-560; The Times, 2. Mai 1864, S. 10; ibid. 11. September 1866, S. 6.

102 Vgl. The Times, 18. Oktober 1866, S. 9.

${ }^{103}$ Vgl. ibid. 30. Juni 1874, S. 5. Vgl. auch BLACKWOOD, London's Immortals, S. 39. Am 3. Juli wurde daher nicht nur das Denkmal enthüllt, sondern auch der gesamte Platz offiziell der Obhut des MBW übergeben. Vgl. zum Folgenden The Standard, 3. Juli 1874, S. 6; The Morning Post, 3. Juli 1874, S. 6.

${ }^{104} \mathrm{Vgl}$. ibid.

${ }^{105}$ Vgl. Lloyd's Weekly Newspaper, 5. Juli 1874, S. 6. 
habe ${ }^{106}$. Shakespeare geriet in der enthusiastischen Deutung zum Repräsentanten von »civilisation « und »virtue ${ }^{107}$, zur Lichtgestalt literarischer Aufklärung, deren Einfluß sich unterschiedslos auf die wvarious strata of our social system« einschließlich der "working classes« und der »labouring population" erstrecke $^{108}$. Mehr noch als die Verkörperung eines literarisch-moralischen Ideals war es diese sozial inklusive Potenz des Poeten zur Beförderung weitreichender Kongruenz innerhalb der Nation, die die Figur zur dezidiert nationalen machte und Shakespeares Dichtung mit der funktionalen Erwartung befrachtete, auf nahezu magische Weise sogar der Beschwichtigung von Sozialkonflikten dienlich sein zu können: »His spirit possesses a talismanic influence as a powerful bond of union between the jarring elements of society. (...) Great monuments of art possess much influence as educating and tranquilizing agents ${ }^{109}$. Als Inklusionsinstrument und Medium öffentlicher Didaxe zugunsten eines breiten Patriotismus sollte ein ästhetisch anspruchsvoll und aufwendig gestaltetes Shakespeare-Monument dann am Ende wirken ${ }^{110}$.

Die zusätzliche Einordnung des Projekts in den Kontext der Weltausstellung von 1851 schien die Chance zu bergen, vom "patriotic desire industrieller und künstlerisch-ästhetischer Selbstdarstellung der Nation, von Modernitätsbewußtsein, Produktionseifer und humanitärer, fast sozialpolitischer Selbstverpflichtung auch für das Denkmalunterfangen zu profitieren ${ }^{111}$. Indessen blieb der emphatische Plan Episode und wurde nicht unmittelbar wieder aufgegriffen.

Neue Vorschläge für ein nationales Shakespeare-Denkmal, die seit Anfang der 1860 er Jahre wieder kursierten, fielen wenig bescheidener, aber konkreter aus. Plädiert wurde dann etwa für ein "national monument«, das auf dem Primrose Hill nördlich des Regent's Park weitab der übrigen metropolitanen Monumente an möglichst exponierter Stelle entstehen sollte ${ }^{112}$. Der Plan war an ein immenses städtebauliches simprovement«-Vorhaben gekoppelt, wonach auf diesem Wege zugleich das Londoner West End mit dem noblen Stadtteil Hampstead verbunden und eine den Pariser Champs Elysées nachempfundene Achsenstraße unter dem Namen Prince of Wales-Avenue neu angelegt werden sollte, von der aus das Nationaldenkmal optimal sichtbar und also von einer royalistisch konnotierten Prachtstraße aus zu einem außergewöhnlichen Blick-

${ }^{106}$ Vgl. [An.,] Proposal for erecting a monument to Shakespeare, read before a meeting of the society of arts, February 5, 1851, H.T. Horpe, Esq., M.P. in the chair, London 1851, S. 6.

${ }^{107}$ Ibid. S. 8.

${ }^{108}$ Vgl. ibid. S. 12.

${ }^{109}$ Vgl. ibid. S. 13 [H. i. O.].

110 Vgl. ibid.

111 Vgl. ibid. S. 15.

112 Vgl. [An.,] Proposed site for the National Monument of Shakespeare (in connection with Park improvements) suggested to the ter-centenary celebration commitee by one of its members, o. O. 1863, up. 
fang der Kapitale würde ${ }^{113}$. In der visionären Tradition blieb schließlich auch der weitere Vorschlag eines Walter Stephens für die Verbindung von Shakespeare-Denkmal und nationalem Theater, der das Denkmal mit dem Bedarf an zivilisatorischem Prestige und didaktisch wirkungsvoller Anleitung zu nicht nur humanitären, sondern dezidiert demokratischen Werten begründete ${ }^{114}$.

Shakespeare was at all times essentially democratic, whilst ever fervently admiring the noble labour, the strenuous perseverance (...) which he saw and knew the people (...) in all the world bore with so much dignified and beautiful patience and which he (...) strove to alleviate and brighten in his intensely humanising and immortal works ${ }^{115}$.

Nicht anders als beim ersten emphatischen Denkmalprogramm erwies sich der Reflex auf die inhomogene und ungleiche Verfaßtheit der Nation zwar als genuiner Bestandteil der Idee vom nationalen Shakespeare-Denkmal, der Rekurs auf strukturelle Realitäten blieb aber sozialromantisch und begnügte sich mit der Ästhethisierung und also künstlerisch aufbereiteten Perpetuierung sozialer Differenzen, statt bis zur sozialreformerischen Kritik vorzudringen ${ }^{116}$.

Der erst visionäre, dann kompensatorische Charakter des Shakespeare-Kults, der die Projekte kennzeichnete, schrumpfte im 1874 entstandenen Denkmal drastisch zusammen. Die Leicester Square-Statue hielt keine Reminiszenz an nationalpolitische Freiheitsrechte oder gar die der »great nation«, sondern als Bestandteil des städtebaulichen Sanierungsprojekts nurmehr eine vage Idee genuiner »Volks«-Nähe des Literaten lebendig.

Weniger sozial- als außenpolitische Konturen gewann die Nationsidee im Zuge der Monumentalisierung des Literaten Lord Byron am 24. Mai 1880 in Hamilton Gardens nördlich von Hyde Park Corner. Mit der Denkmalerrichtung kam eine ganze Serie von gescheiterten Initiativen seit den 1830er Jahren zum Abschluß. Der anglikanische Geistliche Dean Ireland von Westminster Abbey hatte sich zunächst nach Byrons Tod erfolgreich gegen die Aufnahme der sterblichen Überreste Byrons in die nationale Walhalla zur Wehr gesetzt ${ }^{117}$.

${ }^{113}$ Vgl. ibid. und [An.,] Shakespeare's Day: A plea for a monument with a lyric from Romeo and Juliet, London 1864 [up]. Auch ohne das (nie gebaute) Monument fanden Ende April 1864 anläßlich des 300. Geburtstages des Dichters öffentliche Shakespeare-Feiern am Primrose Hill statt, in deren Verlauf Reformer und Protestler die latent radikaldemokratische Konnotation der Shakespeare-Figur dazu zu nutzen versuchten, die Dichterfeier zur pro-Garibaldischen Kundgebung umzufunktionieren. Vgl. ILN, 30. April 1864, S. 413; Lloyds Weekly, 24. April 1864, S. 1. Vgl. TAYLOR, „Common-Stealers", S. 397f; DERS., Shakespeare and Radicalism: the uses and abuses of Shakespeare in nineteenthcentury popular politics, in: HJ 45 (2002) S. 357-379.

${ }^{114} \mathrm{Vgl}$. Walter STEPHENS, The proposed world's tribute to Shakespeare. A plea for the erection of a memorial statue and national Theatre, London o. J., S. 4-5.

115 Ibid.

${ }^{116}$ Vgl. ibid. S. 10.

${ }^{117}$ Vgl. [SYDNEY,] S.'s Letter to the King; and the other correspondence, connected with the reported exclusion of Lord Byron's Monument from Westminster Abbey, London 1828; Henry Austen DRIVER, Byron and the Abbey. A few remarks upon the Poet, elicited by the 
Später fällte das Parlament die Entscheidung, daß eine Büste von Thorwaldsen in die Abbey aufgenommen werden sollte, aber nach einer heftigen Diskussion im House of Lords zwischen dem einem theologisch informierten Rationalismus verpflichteten Whig Lord Brougham und dem Bischof von London Blomfield erhielten erneut die Gegner der Initiative die Mehrheit, indem sie Byrons Beisetzung in der Abbey als Profanierung des ebenso religiösen wie nationalen Kultortes ablehnten ${ }^{118}$.

Als nach langen Jahren des Dissenses schließlich doch eine Einweihungsfeier zustandekam, unterblieb jede Form öffentlicher Inszenierung, während der Aufstellung der Statue auf einem provisorischen Holzsockel lediglich eine kleine Gruppe von unmittelbar in die Initiative Involvierten beiwohnte ${ }^{119}$. Damit waren die Denkmalstifter selbst hinter ihre frühere Absicht zurückgegangen, eine Feier immerhin in bescheidenem Rahmen auszurichten ${ }^{120}$. Dies konnte den Liberalen Lord Houghton nicht davon abhalten, Byron zum intellektuellen und künstlerischen Verbinder der Generationen und geistigen Kontinuitätsstifter Großbritanniens, schließlich aber vor allem zum Helden der politischen sindependence«-Idee zu machen ${ }^{121}$. Zugleich erinnerte Houghton an die von einem breiten romantisch-nationalen und liberalen Philhellenismus getragene Unterstützung des griechischen Unabhängigkeitskampfes gegen das Osmanische Reich durch Byron während der 1820er Jahre ${ }^{122}$. Diese Bemerkung nahm sich nur einen Monat nach dem Regierungswechsel zugunsten der Liberalen 1880 durchaus auch als nachträgliches Verdikt gegen eine für prinzipienlos erachtete konservative Außenpolitik und als forciertes Bekenntnis zu einem liberalen, an Konstitutionalismus und Freiheitsrechten orientierten Interventionismus zugunsten souveräner Nationsgründungen aus.

Im bescheidenen Zeremoniell kam unterdessen erneut zum Ausdruck, daß noch bis in die Spätphase der Initiative hinein die öffentliche Resonanz ambivalent und damit der nationale Kultstatus Byrons zutiefst umstritten blieb. Davon zeugte bis zuletzt nicht nur der schleppende Subskriptionsverlauf, sondern auch die komplizierte Standortsuche. Die Vestry of St. George's HanoverSquare nämlich hatte noch im Frühjahr 1879 die unorthodoxe Haltung Byrons zur anglikanischen Staatskirche zum Argument dafür gemacht, das Ansinnen

rejection of his statue by the Dean of Westminster with suggestions for the erection of a national edifice to contain the monuments of our great men, London 1838.

${ }^{118}$ Vgl. ibid.; The Times, 1. August 1831, S. 7; ibid. 22. August 1838, S. 5; ibid. 5. Juni 1844, S. 1 und Richard EDGCUMBE, History of the Byron Memorial, London 1883. Die Büste fand erst knapp 20 Jahre später im Trinity College, Cambridge, Aufstellung. Vgl. The Times, 11. Februar 1879, S. 8; ibid. 9. November 1876, S. 6.

119 Vgl. Evening Standard, 25. Mai 1880, S. 8.

${ }^{120} \mathrm{Vgl}$. John Murray vom Komitee an das Office of Works, 7. Mai 1880, PRO Work 20/47 [up]. Vgl. auch Murray an das Office, 17. Mai 1880, ibid.

121 Vgl. Evening Standard, 25. Mai 1880, S. 8.

${ }^{122} \mathrm{Vgl}$. ibid. 
des Komitees zurückzuweisen, die Statue in St. James's Street zu plazieren, und damit explizit den Status der nationalen Kultfigur unmittelbar an ein loyales, traditionales Staatskirchentum geknüpft ${ }^{123}$.

Gleichwohl hatte 1875 das engagierte Votum Benjamin Disraelis für die weiterhin umstrittene öffentliche Memorierung Byrons in der Times besondere Beachtung gefunden ${ }^{124}$. Für die frühen Verwerfungen des Literaten versuchte das Blatt die morallastige, von "prejudices«, »animosities« und "hypocrisies" befrachtete Gestimmtheit der nationalen Gesellschaft verantwortlich zu machen und suggerierte im Blick auf das Votum des konservativen Premiers, daß Reformen und Modernisierung der Nation inzwischen nicht nur die Adaption an den rasch voranschreitenden sozio-ökonomischen Wandel, sondern auch ein erhebliches $\mathrm{Ma} ß$ an geistiger Offnung eingetragen hatten, so daß die moralisierende Aufgeregtheit nun einem gelasseneren Urteil würde weichen können $^{125}$. Indessen erwies sich die optimistische Prognose über den nationalen Konsenseffekt der Byron-Figur als deutlich verfrüht, und bedingten nicht zuletzt spärliche Fonds, daß die Denkmalunternehmung jener »nation«-weiten Resonanz entbehrte, die sich die Initiatoren erhofft hatten ${ }^{126}$.

Immerhin kam es in den folgenden Jahren zu spontanen Gedächtnisakten am Denkmal, wenn Verehrer des Poeten am Jahrestag seines Todes Kränze niederlegten ${ }^{127}$. Dem Versuch propagandistischer Überformung des monumentalen Zeichens wurde aber rasch Einhalt geboten. So verweigerte der First Commissioner of Works auf Anfrage eines Demonstration Committee of the Cretan Protest Procession ${ }^{128}$, die im April 1897 eine Kundgebung im Hyde Park plante, eine Kranzniederlegung an der Byron-Statue, weil in der "political demonstration« zumal andersnationaler Gruppierungen vor der Statue Byrons eine nicht tolerable Sinnverfälschung des überparteilich konzipierten Monuments gesehen wurde ${ }^{129}$. Der Versuch kretischer Interessenvertreter, den eigenen Unabhängigkeitskampf gegen das Osmanische Reich, der seit einem Jahr mit der Unterstützung Griechenlands tobte, symbolisch von der Peripherie der imperialen Mächte ins europäische Zentrum zu tragen, wurde damit unterbunden. Damit bemühte sich die politische Führung Großbritanniens, eine entsprechende Loyalitätswerbung für die mit traditioneller Solidarität mit den nationalen Befreiungsbewegungen konnotierte Figur Byrons in der briti-

${ }^{123} \mathrm{Vgl}$. The Times, 22. April 1879, S. 9.

${ }^{124} \mathrm{Vgl}$. ibid. 17. Juli 1875, S. 11.

${ }^{125} \mathrm{Vgl}$. ibid.

${ }^{126}$ Vgl. Evening Standard, 25. Mai 1880, S. 8; The Daily Telegraph, 25. Mai 1880, S. 3; Fraser's Magazine N.S. 19 (Mai 1879) S. 665-666.

${ }^{127}$ Vgl. Anfrage einer Mary Wilson beim Office of Works vom 13. April 1890, PRO Work 20/47 [up].

${ }^{128}$ Vgl. Brief des Demonstration Committee an den First Commissioner, 7. April 1897, PRO Work 20/47.

${ }^{129}$ Vgl. Replik des First Commissioners vom 9. April 1897, PRO ibid. 
schen Öffentlichkeit zu vereiteln und eine politisierte Lesart des Monuments überhaupt zu unterbinden.

Konkurrierende Nationsentwürfe, die allerdings im Rahmen einer selektiven Rezeption nicht zum offenen Dissens führten, provozierte demgegenüber die Errichtung eines Denkmals für den Philosophen und politischen Publizisten Thomas Carlyle Ende Oktober 1882 am Chelsea Embankment, ganz am östlichen Ende von Chelsea, wo er lange gelebt hatte ${ }^{130}$. Der Physiker, Populärwissenschaftler und langjährige Freund Carlyles, John Tyndall, bescheinigte Carlyle weitreichenden Einfluß, der die Sphäre des Politischen überstieg, indem er mit seinen Schriften mindestens eine ganze Generation geprägt und das Bewußtsein der nationalen Gesellschaft seit den 1840er Jahren unablässig ebenso infiltriert wie diagnostisch abgespiegelt habe ${ }^{131}$. Autoritätskritik und Demokratieskepsis identifizierte Tyndall als Grundprämissen Carlylescher Denkart. Einerseits habe Carlyle nämlich der aristokratisch dominierten politischen Führung Dilettantismus in Zeiten der ökonomischen und sozialen Krise vorgeworfen, andererseits dem Chartismus der 1840er Jahre ein Recht auf Protest gegen das Versagen der politischen Elite und ein unerträglich gewordenes Armutsgefälle zugestanden, nicht aber auf Etablierung einer egalitären Demokratie, in der Carlyle keine Chance auf Abhilfe gegen die Mißstände der Zeit $\operatorname{sah}^{132}$. „Work«, »military virtues« und am Ende auch ein religiöses Gottesbekenntnis benannte Tyndall als zentrale, militärisch angereicherte viktorianische Wertvorgaben Carlyles und zugleich wünschenswerte Entwicklungsrichtlinien für die Nation ${ }^{133}$.

Der Standard nahm Carlyle noch stärker für eine konservative Idee der nationalen Gesellschaftsordnung in Beschlag, wonach der waristocracy« das Privileg der Führung des "people« vorbehalten war ${ }^{134}$. Dabei vergaß er nicht, jene Kautelen zu erörtern, unter denen Carlyles Thesen in der Tat standen, indem er der Forderung Nachdruck verlieh, daß dann die aristokratische Führungselite unter umso höherem Qualifikationsdruck stand, ihre Berechtigung zur sozialen und politischen Suprematie nachzuweisen und Akzeptanz einzuwerben ${ }^{135}$. Adaptionsbedarf der Theorie machte der Standard gleichwohl geltend, indem er Carlyles Urteil über die regenerationsbedürftige Aristokratie als überzogen verwarf, während er daran festhielt, sthat subordination is the law of human society, and that nations are only happy in proportion to their observance of

${ }^{130}$ Vgl. zum Folgenden The Times, 27. Oktober 1882, S. 8; The Evening Standard, 27. Oktober 1882, S. 8; The Standard, 27. Oktober 1882, S. 3; The Daily Telegraph, 27. Oktober 1882, S. 5 .

${ }^{131}$ Vgl. ibid.

${ }^{132} \mathrm{Vgl}$. ibid.

${ }^{133}$ Vgl. ibid.

${ }^{134}$ Vgl. The Standard, 27. Oktober 1882, S. 5.

${ }^{135}$ Vgl. ibid. 
it $\kappa^{136}$. Autoritarismus unter der Prämisse qualitativ besserer und providentiell vorbestimmter aristokratischer Herrschaft wurde damit zum Grundprinzip des konservativen Nationskonzepts, zu dem sich der Standard anläßlich der Denkmaleinweihung bekannte ${ }^{137}$. Der liberale Daily Telegraph hingegen deutete das Denkmal als Indiz für eine Liberalisierung der öffentlichen Symbollandschaft, sofern Carlyle vor dem Hintergrund seiner frühen Schriften, in denen er Verständnis für Hungerrevolten und Sozialprotest artikuliert hatte, immerhin des politischen Radikalismus geziehen worden war $^{138}$. Dem Telegraph zufolge stand Carlyle nun ganz anders als in Tyndalls Rede weniger für ein autoritäres Herrschaftsverständnis, als für ein gründliches und für eine ganze politische Generation handlungsleitendes Räsonieren über die "formulae of liberalism and progress«, an denen sich die Nation künftig würde orientieren müssen, wollte sie inmitten das Wandels bestehen ${ }^{139}$.

Freilich unterblieb der Versuch, Egalitäts- oder Partizipationspotentiale auszuloten, die der Carlylesche Liberalismus-Begriff womöglich kaum barg. Nur unter der Bedingung mancher Differenzierung äußerte sich mit dem Nonconformist and Independent auch eines der führenden Organe des Dissent zustimmend $^{140}$. Zum Helden des »improvement« stilisierte das Blatt Carlyle dann allerdings gerade unter Absehung von seinen politischen Thesen und schloß in diese Ausklammerung Carlyles Absage an eine partizipatorische Ordnung der Nation wenigstens indirekt ein ${ }^{141}$. Statt dessen bekannte sich der Nonconformist and Independent zur Carlyleschen Ethik, die die Benthamistischen Maxime vom größtmöglichen Glücksgenuß als Endziel des Individualismus mit einer Fundamentalkritik an der materialistischen, kompetitiven Industriegesellschaft konterte und Tugendwerte wie »duty« und »religious spirit« zur moralischen Regeneration empfahl ${ }^{142}$. Die Differenzierung zwischen politischer und ethischer Lehre bildete mithin die Voraussetzung für das Bekenntnis auch der tendenziell liberalen Presse zum nationalen Heroentum Carlyles ${ }^{143}$.

Symptomatisch für die linke Presse schließlich äußerte sich der Manchester Guardian angesichts der Denkmaleinweihung äußerst verhalten und beschränkte sich bei der Wiedergabe von Tyndalls Rede auf jene Sequenz, die die Parteinahme Carlyles zugunsten der sozialen Protestbewegungen Anfang

${ }^{136}$ Ibid.

137 Vgl. ibid.; aber relativierend The Evening Standard, 27. Oktober 1882, S. 2.

${ }^{138}$ Vgl. The Daily Telegraph, 27. Oktober 1882, S. 5.

139 Vgl. ibid. 28. Oktober 1882, S. 5.

${ }^{140} \mathrm{Vgl}$. The Nonconformist and Independent, 2. November 1882, S. 1029.

141 Vgl. ibid.

${ }^{142} \mathrm{Vgl}$. ibid.

${ }^{143}$ Vgl. nach dieser Maßgabe auch den knappen Kommentar in The Spectator, 28. Oktober 1882, S. 3. 
der 1840er Jahre thematisierte, während das Verdikt gegen die Demokratie durch eine Paraphrase entschärft wurde ${ }^{144}$.

Somit dienten auch hier Auslassungen dem Zweck, die nationale Konsensrhetorik der Denkmalstifter nicht unterlaufen zu müssen. Gegenüber dem dezidiert autoritären Herrschaftsideal, das der politische Konservativismus im Blick auf die Carlyle-Figur vertreten hatte, blieben liberale und linke Deutungen vage. Damit machte man sich über alle parteipolitischen Differenzen hinweg jenes Credo zu eigen, mit dem Carlyle in seiner Schrift »On Heores and Hero-worship« bereits 1841 an die Öffentlichkeit getreten war und aus der sich die Kultambition des Jahrhunderts seither zu speisen begonnen hatte, indem die moderne Gesellschaft sich aufgefordert sah, in der Identifizierung und dem Kult ihrer Helden ihre Existenzfähigkeit unter Beweis zu stellen ${ }^{145}$. Der subversive Effekt der Heldenthese, der ihr in den 1840er Jahren frühe Popularität gerade der Chartisten und Radikalen eingetragen hatte, sofern sich wohl Cromwell und Napoleon, nicht aber ein Dynast unter den Carlyleschen wheroes $«$ befand und als ideale Konditionen der Heldengeburt die Revolution rangierte $^{146}$, bedingte indessen ihre komplette Auslassung aus der Festrhetorik von 1882. Carlyles ambivalente Rolle als radikaler Konservativer ließ die Denkmalfigur zur Projektionsfläche kollidierender Deutungsmuster werden, während die konservativen Interpreten mit dem Zeremoniell auch die Rezeption beherrschten.

Mit dem im Juli 1884 entstandenen Denkmal für Robert Burns am Victoria Embankment rückte erstmals die Nation als multinationales Königreich und die Situierung der schottischen Nation im multinationalen Verband in den Interessenmittelpunkt der Sinnproduzenten. Zur Einweihungsfeier jedenfalls fanden sich einige wenige Verehrer des schottischen Poeten aus dem Parlament und als Komiteepräsident der in Cambridge lehrende Naturphilosoph James Dewar ein ${ }^{147}$. Der schottische Geschäftsmann John Gordon Crawford als Stifter des Denkmals begründete seine Initiative noch einmal damit, als "Scotsman « ein Geschenk in der britischen Metropole und ein Zeichen öffentlicher Anerkennung angesichts der hier wirkenden »free institutions« hinterlassen zu wollen. Im "national poet of Scotland" sah er die geeignete Figur, die die symbolische Verbindung zwischen dem partikularen Eigenbewußtsein

${ }^{144} \mathrm{Vgl}$. The Manchester Guardian, 27. Oktober 1882, S. 8. Noch knapper fiel die Erwähnung der Inauguration in Reynold's Newspaper, 29. Oktober 1882, S. 6, aus, während Lloyd's Weekly Newspaper auf einen Bericht ganz verzichtete.

${ }^{145} \mathrm{Vgl}$. Thomas CARLYLE, On heroes and hero-worship and the heroic in history, London 1901, S. 202. Vgl. dazu Malcolm HaRDMAN, Six Victorian Thinkers, Manchester 1991, S. 33-39.

${ }^{146} \mathrm{Vgl}$. CARLYLE, On heroes, S. 204.

${ }^{147}$ Vgl. The Standard, 28. Juli 1884, S. 3; The Moming Post, 28. Juli 1884, S. 6; The Times, 28. Juli 1884, S. 3. 
der Schotten und der vielgestaltigen Denkmallandschaft der Metropole herstellen konnte ${ }^{148}$.

Der Liberale Earl of Rosebery huldigte Burns mit den Worten der Denkmalinschrift, die er eigens zitierte: "The poetic genius of my [i.e. Burn's, H.R.] country found me at the plough (...). She bade me sing the loves, the joys, the rural scenes, and rural pleasures of my native soil in my native tongue ${ }^{149}$. Danach wirkten agrarromantische Schollengebundenheit und die intensiv zelebrierte Gemeinschaft der Muttersprache als emphatische und gleichsam schicksalhaft mitgegebene Adhäsionskräfte zugunsten der "nation«, der sich das empfängliche Individuum nicht entzog, die es vielmehr in poetische Schaffenskraft verwandelte und vermittels der Kunst noch potenzierte. Gerade indem er die "conception of the peasant" in den Mittelpunkt seiner Literatur stellte, wuchs Burns nach Roseberys Überzeugung endgültig über den Geltungsbereich der schottischen mindestens zugunsten der britischen Nation, wo nicht der gesamten Welt, hinaus. Er transzendierte die Nationalität dank der Verpflichtung auf die universalen Werte von »nature« und »humanity« und gewann statt einer nations- nun klassenspezifische Repräsentanz:

It is for that reason that all the labouring classes - the masses of the world - have found in Burns their truest friend. (...) It is true, strangely enough, that he belonged to that very class the enfranchisement of which is discussed at this moment. But I believe that (...) the following of the plough was a distinct advantage to Robert Bums, that it gave him those opportunities for long meditation and long communion with nature to such rich account afterwards ${ }^{150}$.

Über der sozialen Zuordnung geriet nun statt Burns' geistiger Repräsentativität für die Kulturnation seine Zugehörigkeit und Partizipationsberechtigung an der politischen Nation qua sozialer Abkunft zum Thema von Roseberys Rede, und bot Gelegenheit, auf den 1884 von der liberalen Gladstone-Regierung verabschiedeten Representation of the People Act anzuspielen, der die Wahlberechtigung für die Landarbeiter in den Counties erweiterte, obschon - wie Rosebery freilich nicht erwähnte - weitere Ungleichheiten und Exklusionsmechanismen zu Ungunsten der Unterschichten anhielten ${ }^{151}$. Burns Zuordnung zu den »labouring classes« provozierte nun keine Egalitätsfiktionen, sondern ließ Rosebery die soziale Differenz in nachgerade grotesker Manier zum künstlerischen Inspirationsvorteil umdeuten, veranlaßte mithin zu wohlfeiler Ästhetisierung und Romantisierung der Ungleichheit und wenig mehr als quietistischer Beschwichtigung. Roseberys Deutungsmuster trug - durchaus spiegelbildlich für das Politikverständnis der Gladstone-Regierung - am Ende deutlich die Handschrift des »Liberal aristocrat«, der den Bedarf an erhöhter Partizipation

\footnotetext{
$148 \mathrm{Vgl}$. ibid.

149 Ibid. Das Burns-Zitat entstammte der Widmung einer ersten in Kilmarnock publizierten Ausgabe der Gedichte, vgl. The Times, 28. Juli 1884, S. 3.

${ }^{150}$ The Standard, 28. Juli 1884, S. 3.

${ }^{151}$ Vgl. hier nur PARRY, The rise and fall of Liberal Government, S. 280-287.
} 
erkannte, ohne die Exklusivität einer regierenden Elite und die Exklusion derjenigen Bevölkerungsteile aufgeben zu wollen, die aus sozialdefensiver Perspektive unter Radikalismus-Verdacht standen.

Der Standard stimmte mit Rosebery überein, daß die künstlerische Aufbereitung der "past history and independence of Scotland« und also die literarisch-ästhetische Pflege eines nationalen Geschichtsbewußtseins Burns in den Rang der Kultfigur erhoben ${ }^{152}$. Auch er sah sich nicht veranlaßt, die Traditionspflege des Schottentums als partikularistische Gefährdung eines dezidiert britischen Kollektivbewußtseins zu beargwöhnen. Entsprechende Polarisierungen fehlten aber vor allem, weil die Grundwerte, für die Burns in Anspruch genommen wurde, mit einer nahezu mystischen Naturverbundenheit und humanistisch-ethischen Tugendidealen derart universalistisch konzipiert blieben, $\mathrm{da} B$ sie gerade die Exportfähigkeit des schottischen Nationalismus Burns'scher Provenienz zu dokumentieren geeignet waren.

Burns' Status als "greatest Scotsman« allerdings wollte der Standard unbedingt relativieren und zog es aus politischen Gründen vor, diese Repräsentativität statt dessen dem zweiten großen Literaten Schottlands, Sir Walter Scott ${ }^{153}$, zuzuerkennen:

Burns had been a Jacobite in his youth (...) and afterwards (...), a Radical. Scott was a steady Tory, one whose writings did more to arrest the progress of revolutionary ideas in this country than all the Acts of all the politicians put together. (...) Hence Whig and Liberal politicians have always slightly looked askance at him (...). But the space which Scott fills in our history and our literature must always be larger than the place filled by Burns ${ }^{154}$.

Der Standard favorisierte Scott als nationale Kultfigur, weil er beträchtliche politische Vorbehalte gegenüber den philanthropisch-reformerischen, tendenziell revolutionären Konnotationen hegte, die ein entlang des Burns'schen Denkens entwickelter Nationsbegriff würde erhalten können. Scott hingegen galt ihm als verläßlicher Antirevolutionär und Vertreter eines reaktivierten, unter den Bedingungen sozioökonomischen Wandels dynamisierten Konservativismus.

Weder in den Festreden noch in den Pressekommentaren mündete dabei der Versuch, Burns zum nationalen Repräsentanten zu stilisieren, in eine distinkte Begrifflichkeit von schottischer versus britischer oder englischer Nationalität. Die konzeptionelle Inklusion Schottlands vollzog sich hier eher auf dem Wege einer Parallelisierung mit jenem ruralen und nostalgisch-rückwärtsgewandten Englishness-Konstrukt, das während der zweiten Hälfte des 19. Jahrhunderts weniger als populäre denn als minoritäre und elitäre Vision der Nation in

${ }^{152} \mathrm{Vgl}$. The Standard, 28. Juli 1884, S. 3.

${ }^{153} \mathrm{Vgl}$. auch [An.,] Speech of John Hay at the unveiling of the bust of Sir Walter Scott in Westminster Abbey, May 21, 1897, London 1897.

154 The Standard, 28. Juli 1884, S. 3. 
England vertreten wurde ${ }^{155}$. Burns' Schottland sollte auf diesem Wege gleichsam mit den entsprechenden ländlichen England-Versionen kompatibel und am Ende subsumierbar erscheinen, so daß eine Art schleichende Inklusion von schottischer und englischer Nation impliziert war, deren ausdrückliche Thematisierung indessen gemieden wurde.

Plebiszitäre Konnotationen der Shakespeare-Figur, die Assoziation einer emanzipatorisch-liberalen Interventionspolitik im Blick auf Byron, ein kontroverser Diskurs über eine autoritäre oder partizipatorische nationale Ordnung und schließlich die Amalgamierung der multinationalen Nation im Umfeld des Burns-Monuments bildeten einen höchst heterogenen Themenkatalog, der angesichts der Literaten- und Denker-Figuren diskursiv entfaltet wurde. Dabei erschienen die Denkmäler zwar nicht als willkürliche Projektionsflächen jeweils aktueller innen- und außenpolitischer Konfliktlagen, entsprechende thematische Konjunkturen beeinflußten ihre Inszenierung und offiziöse Deutung gleichwohl deutlich ${ }^{156}$.

\section{Vergleich}

Die Prominenz des Festpublikums anläßlich der Einweihung von Künstlerdenkmälern vor allem in Paris und Berlin zeugte von der besonderen Relevanz, die Denkmalinitiatoren und staatliche Autoritäten gleichermaßen dem Kultpersonal beimaßen. In Paris bildete die in ausladende Feierlichkeiten für einen der renommiertesten grands hommes der Dritten Republik integrierte Einweihung des Hugo-Denkmals den Anlaß für einen öffentlichen Auftritt von Ministerund Staatspräsidenten, in Berlin nahm der Kaiser sowohl an der Schiller- als auch an der Goethe-Feier teil, während er sich anläßlich der Lessing-Feier immerhin von einem der Prinzen vertreten ließ. Die Berliner Schiller-Feier wies stärker als die folgenden Feste eine Art zeremoniellen Transitionsstatus auf. Einerseits blieben rituelle Elemente der nachmärzlichen Schiller-Feiern wie die auch auf die nichtpreußischen Einzelstaaten rekurrierende deutsche Fahne, die zahlreiche Teilnahme von Studenten und Sängern und die Denk-

${ }^{155}$ Vgl. zur »Englishness«-Debatte Peter MANDLER, Against »Englishness«: English culture and the limits to rural nostalgia, 1850-1940, in: TRHS $6^{\text {th }}$ ser. VII (1997) S. 155-175.

${ }^{156}$ Freilich geschah dies keineswegs automatisch. Völlig marginal blieben gegenüber den genannten Denkmalsetzungen etwa diejenige für den Maler Sir John Millais, die eine kleine Gruppe von Künstlerkollegen unter der Patronage König Edwards VII. betrieben hatte und die im November 1905 vor der Tate Gallery ohne offizielle Feier stattfand. Vgl. Mitteilung des Bildhauers Thomas Brock an das Office of Works, 22. Oktober 1904; Bericht des Office of Works an die Treasury, 11. Dezember 1905, PRO Work 20/56 [up]; The Pall Mall Gazette, 23. November 1905, S. 9. 
malumrundung als Akt der symbolischen Aneignung erhalten. Andererseits stellten die Aussperrung des restlichen Festpublikums, der Ausschluß von Frauen und die wenn auch distanzierte Teilnahme des Kaisers untrügliche Indizien einer machtstaatlichen Okkupation des Rituals dar, während umgekehrt keinerlei militärische Symbole in das Zeremoniell Eingang fanden.

In programmatischer Hinsicht spiegelte sich im Heer der Pariser Künstlerdenkmäler der Gedanke vom nationalen Vermögen der Kunst im allgemeinen und der Literatur im besonderen wider, die einerseits schichtenindifferent rezipiert wurde und daher einend wirkte und die nationale Gemeinschaft auf humanitäre und zivilisatorische Werte verpflichtete, ihr andererseits nach außen Prestigezugewinne und internationalen Respekt vor der Kulturleistung der Franzosen eintrug. Vor dem Hintergrund dieses Selbstbewußtseins war durchaus auch die Absorption fremdnationalen Personals in die Riege der grands hommes praktikabel. $\mathrm{Zu}$ den gängigsten Assoziationen zählte eine Art nationale Theorie der literarischen Sprache, die die generationelle Vernetzung der nationalen Gesellschaft als dauerhafte Erinnerungsgemeinschaft gestattete. Mit dem Gros der Pariser Künstlerdenkmäler waren insofern am ehesten die Berliner Denkmäler für Chamisso und Fontane vergleichbar, die dort als Projektionshintergrund harmonisch-inklusiver Nationsbegriffe dienen konnten und deren Stifter dem intellektuellen und kulturellen Grenzgängertum Vorteile abgewannen, Transnationalität gerade in Richtung Frankreich und Kosmopolitismus als diskursive Chance begriffen.

Die Pariser Standbilder für Hugo und Zola atmeten demgegenüber den Geist des tagespolitischen Diskurses und trugen republikanischen Bekenntnischarakter, indem sie den intellectuel engagé über allen Zusammenbrüchen, Systemwechseln und Krisen der französischen Gesellschaft als authentischen Künder republikanisch-nationaler Werte aufriefen und die Nation als Willensund Gesinnungsgemeinschaft überzeugter und demokratisch-wehrhafter citoyens thematisierten. In Berlin kam nach unemphatischem Auftakt mit der Statue für Hegel im Schiller-Denkmal - der Hugo-Ehrung nicht unähnlich - der nationale Heros par excellence zu Denkmalehre. Anders als dies für Pariser oder Londoner Denkmäler je der Fall war, spiegelte sich nun aber im Diskurs um die Berliner Schiller-, Goethe- und Lessing-Denkmäler je neu die nationale Umbruchserfahrung von 1871 wider. Die Grundsteinlegungsfeier zum Schiller-Denkmal 1859 hatte bereits Sinnstiftungskollisionen entlang soziopolitischer Konfliktlinien zutage treten lassen. Den Charakter des (bildungs)bürgerlichen Oppositionsfestes trug der Berliner Schiller-Kult 1871 nicht mehr. Statt dessen zeichnete sich ab, daß die Symbolmacht auf die Seite des autoritären Staates gewechselt hatte und sich dort bürgerlicher Zustimmung sicher sein konnte. Gleichwohl blieb die mit Schiller assoziierte Nation ambivalent. Aller autoritär-machtstaatlichen Ausrichtung zum Trotz, derzufolge Schiller als Inkarnation des saturierten Einheitsstaats gelten sollte, überstieg 
die Deutung des Literaten als verheißungsvollen Künders nicht nur der geeinten, sondern auch der freiheitlichen Nation noch nach 1871 wieder die Schwelle der Latenz. Die bürgerlichen Träger des Kults selbst erinnerten jene Werthaltungen, aus denen sich die auf Schiller projizierten Nationsideale in den Jahren vor der Staatsgründung gespeist hatten. Zum Teil wurde aber auch der qualitative Umschlag von der Dichter- zur siegreichen »Thäter«-Nation als machtpolitischer und emanzipatorischer Zugewinn verbucht. Egalisienungsappelle und sozialrevolutionäre Verheißung blieben unterdessen auf das sozialdemokratische Meinungslager beschränkt.

Die Reichsgründungszäsur schlug sich im Goethe-Kult in einem zügigen Verschleiß traditioneller Sinnzuschreibungen nieder, während Goethe unter Kosmopolitismusverdacht als Bürge für die deutsche Reichsnation nicht mehr verläßlich erschien. Demgegenüber geriet die Lessing-Figur schließlich in einen Exklusionsdiskurs, in den sie die Konservativen zwangen, die der Amalgamierung von Nation und emanzipatorisch-weltlicher Geisteshaltung mißtrauten und die Herausbildung eines jüdischen Sonderbewußtseins im Schutze eines liberalisierten Nationsbegriffs argwöhnten. Ambivalenz, Redundanz und Exklusion erwiesen sich damit als diskursive Folgeeffekte der Reichsgründungszäsur, für die es in den beiden anderen europäischen Kapitalen keine Äquivalente gab. Im Spiegel des Berliner Wagner-Denkmals leuchtete demgegenüber ein hermetisch-kulturmissionarischer Diskurs auf, der die Internationalität nicht um des Austauschs, sondern um der Dominanz willen suchte und den Nationsbegriff mit einer vagen Volks-Mystik unterlegte. Im Umfeld des Treitschke-Denkmals schließlich wurde, von den vielfachen Exklusionsrhetoriken absehend, der borussianische Geschichtsmythos und damit der Tenor der großen Monarchendenkmäler einmal mehr beschworen ${ }^{157}$.

Eine der Berliner Situation vergleichbare Heterogenität von Projekten für höchst unterschiedliche Repräsentanten einer national konnotierten Kultur zeichnete sich auch in London, hier freilich wieder unter höchst eigenen und dem deutschen Fall fremden Themenvorgaben ab. Dort brachen sich weniger mit dem faktisch errichteten als mit den unverwirklicht gebliebenen Denkmalplänen für Shakespeare-Monumente quasi-plebiszitäre Visionen Bahn, indem die Dichterfigur auf der Seite des Volks und der sozial Benachteiligten verortet, gar als Bändiger von Sozialkonflikten anvisiert wurde, während der Reflex auf die Ungleichheit der nationalen Gesellschaft ästhetisierend und sozialromantisch verfremdet blieb. Aspekte der imperialen Nation flossen in die Pro-

${ }^{157}$ Im Blick auf die Erosionserscheinungen der Figurenkategorie ist Nipperdeys These zuzustimmen, daß die deutschen whistorisch-kulturellen Nationaldenkmäler « für renommierte Geistesgrößen unter den Bedingungen der allgemeinen Denkmalinflation einmal weniger als Symbole mit einem politisch aktivierenden oder gar integrierenden Effekt taugten. Vgl. NIPPERDEY, Nationalidee und Nationaldenkmal, S. 556-559. Zumindest für Berlin ist dessenungeachtet an einem erheblichen Maß offfentlicher Politisierung festzuhalten. 
jekte gleichermaßen ein, implizierten aber Fraternisierungs- statt Machtutopien. Der Verdacht mangelnder Nähe zur anglikanischen Staatskirche, die für die Apostrophierung als nationale Kultfigur zur nicht hintergehbaren Voraussetzung erklärt wurde, verhinderte demgegenüber lange ein Monument für Byron, das seine Apologeten im Namen einer an Konstitutionalismus und Freiheitsrechten orientierten Nationsidee forderten; kultischer Verschleiß über die langen Jahre der öffentlichen Querelen hinweg sorgte aber auch hier für eine unemphatische Inszenierung der Kultfigur.

Der ebenso radikale wie konservative Grundzug seines politischen und philosophischen Werks ließ Carlyle demgegenüber in den 1880er Jahren zur Kultfigur avancieren, die breiten Konsens auf sich vereinen konnte, weil sie äuBerst disparaten Nationsideen Anknüpfungspunkte bot. Sozialkonservativ-autoritäre Ordnungskonzeptionen konnten sich hier ebenso anlagern wie partizipatorische und egalitäre Postulate für die nationale Gesellschaft. Demokratiekritik und die Forderung nach Teilhaberechten des Volks standen damit ebenso unvermittelt nebeneinander, wie sie dies bisweilen in Carlyles Schriften selbst taten. Das hohe Ausmaß an Konsens zur Denkmalsetzung für Carlyle hatte insofern keinerlei programmatische Entsprechung, war also auch keiner neuen Konvergenz eines politischen Nationsbegriffs im England der 1880er Jahre, sondern der spezifischen Disparität des Carlyleschen Werks und einer extrem selektiven öffentlichen Rezeption geschuldet.

Im Spiegel der Burns-Figur trat schließlich die Konstituierung des britischen Königreichs als multinationales Ensemble in den Blick, aus dem nun Schottland herausgegriffen und zur Nation ins Verhältnis gesetzt werden sollte. Im Zuge öffentlicher Sinnzuschreibungen ist dabei gerade keine dichotomische Begrifflichkeit für die englische, schottische oder britische Nation entfaltet, sondern das Spezifikum der schottischen glättend zugleich als das der Gesamtnation identifiziert und eine absolute Kompatibilität der britischen Nationalitäten suggeriert worden. Die harmonistische Deutung zehrte von einer extrem unkonturierten Idee der von Burns verkörperten Nation, die sich der offiziellen Diktion nach in ruraler Beschaulichkeit, mystischer Naturnähe und humanistischen Tugendidealen erschöpfte und von daher kompatibel erschien. Ein Diskurs über die Sprengkraft partikularer Sondertraditionen der britischen Nationalitäten konnte auf diesem Wege umgangen werden. 
